OPEN ACCESS

Edited by:

Lijun Rong,

University of Illinois at Chicago,

United States

Reviewed by:

Gong Cheng,

Tsinghua University, China

Liying Ma,

China CDC NAIDS, China

${ }^{*}$ Correspondence:

Tianlei Ying

tlying@fudan.edu.cn

Shibo Jiang

shibojiang@fudan.edu.cn

Fei Yu

shmyf@hebau.edu.cn

${ }^{\dagger}$ These authors have contributed

equally to this work

Specialty section:

This article was submitted to

Virology,

a section of the journa

Frontiers in Microbiology

Received: 29 September 2019

Accepted: 08 November 2019

Published: 06 December 2019

Citation:

Wang L, Liang R, Gao Y, Li Y,

Deng $X$, Xiang $R$, Zhang $Y$, Ying $T$,

Jiang $S$ and Yu F (2019) Development

of Small-Molecule Inhibitors Against

Zika Virus Infection.

Front. Microbiol. 10:2725.

doi: 10.3389/fmicb.2019.02725

\section{Development of Small-Molecule Inhibitors Against Zika Virus Infection}

\author{
Lili Wang ${ }^{1 \dagger}$, Ruiying Liang ${ }^{2 \dagger}$, Yaning Gao ${ }^{3 \dagger}$, Yanbai Li $^{2}$, Xiaoqian Deng ${ }^{2}$, Rong Xiang ${ }^{2}$, \\ Yina Zhang ${ }^{2}$, Tianlei Ying ${ }^{4 *}$, Shibo Jiang ${ }^{4 *}$ and Fei $\mathrm{Yu}^{2 *}$ \\ ${ }^{1}$ Research Center of Chinese Jujube, Hebei Agricultural University, Baoding, China, ${ }^{2}$ College of Life and Science, Hebei \\ Agricultural University, Baoding, China, ${ }^{3}$ Department of Natural Medicines, School of Pharmaceutical Sciences, Peking \\ University, Beijing, China, ${ }^{4}$ MOE/NHC/CAMS Key Laboratory of Medical Molecular Virology, School of Basic Medical \\ Sciences, Shanghai Medical College, Fudan University, Shanghai, China
}

In recent years, the outbreak of infectious disease caused by Zika virus (ZIKV) has posed a major threat to global public health, calling for the development of therapeutics to treat ZIKV disease. Here, we have described the different stages of the ZIKV life cycle and summarized the latest progress in the development of small-molecule inhibitors against ZIKV infection. We have also discussed some general strategies for the discovery of small-molecule ZIKV inhibitors.

Keywords: Zika virus, life cycle, small-molecule inhibitor, treatment, mechanism

\section{INTRODUCTION}

Zika virus (ZIKV) is an arthropod-borne virus (arbovirus) belonging to the family Flaviviridae and genus Flavivirus. As a single-stranded positive RNA virus, the genome of ZIKV is approximately $10 \mathrm{~kb}$ and encodes three structural proteins and seven non-structural proteins (Wang et al., 2016). In 1947, ZIKV was discovered and isolated from a sentinel Rhesus monkey in the Zika Forest of Uganda (Dick et al., 1952). However, it was only in 2015 that the first outbreak of ZIKV-caused diseases was reported in Brazil (Petersen et al., 2016) with more than one million cases. Since then, it rapidly spread to 84 countries around world, particularly in South America, rendering ZIKV a public health threat (Han and Mesplede, 2018; Figure 1).

Mild symptoms include fever, rash, headache, and joint pain, but the major concern involves the potential for severe neurological disorders, such as microcephaly, neurological disorders in newborns, meningo-encephalitis, Guillain-Barré syndrome, myelitis, and ocular abnormalities (Barros et al., 2018). Until now, neither a specific antiviral drug nor a vaccine has been developed to prevent or cure ZIKV infection. However, several well-characterized drug targets encoded by the virus, or presented in host cells, may help us prevent or treat ZIKV infection. In this review, we focus on current progress on the research and development of small-molecule ZIKV inhibitors, either viral or host cell inhibitors, targeting different stages of the ZIKV life cycle. Such data are essential to the design of drugs and drug delivery modalities against ZIKV and related viruses.

\section{ZIKV LIFE CYCLE AND POTENTIAL TARGETS FOR THE DEVELOPMENT OF SMALL-MOLECULE INHIBITORS AGAINST ZIKV INFECTION}

The life cycle of ZIKV can be divided into four stages, including virus entry, genome replication, virus assembly, and release. Mature ZIKV particles first adhere to host cells by interacting with 


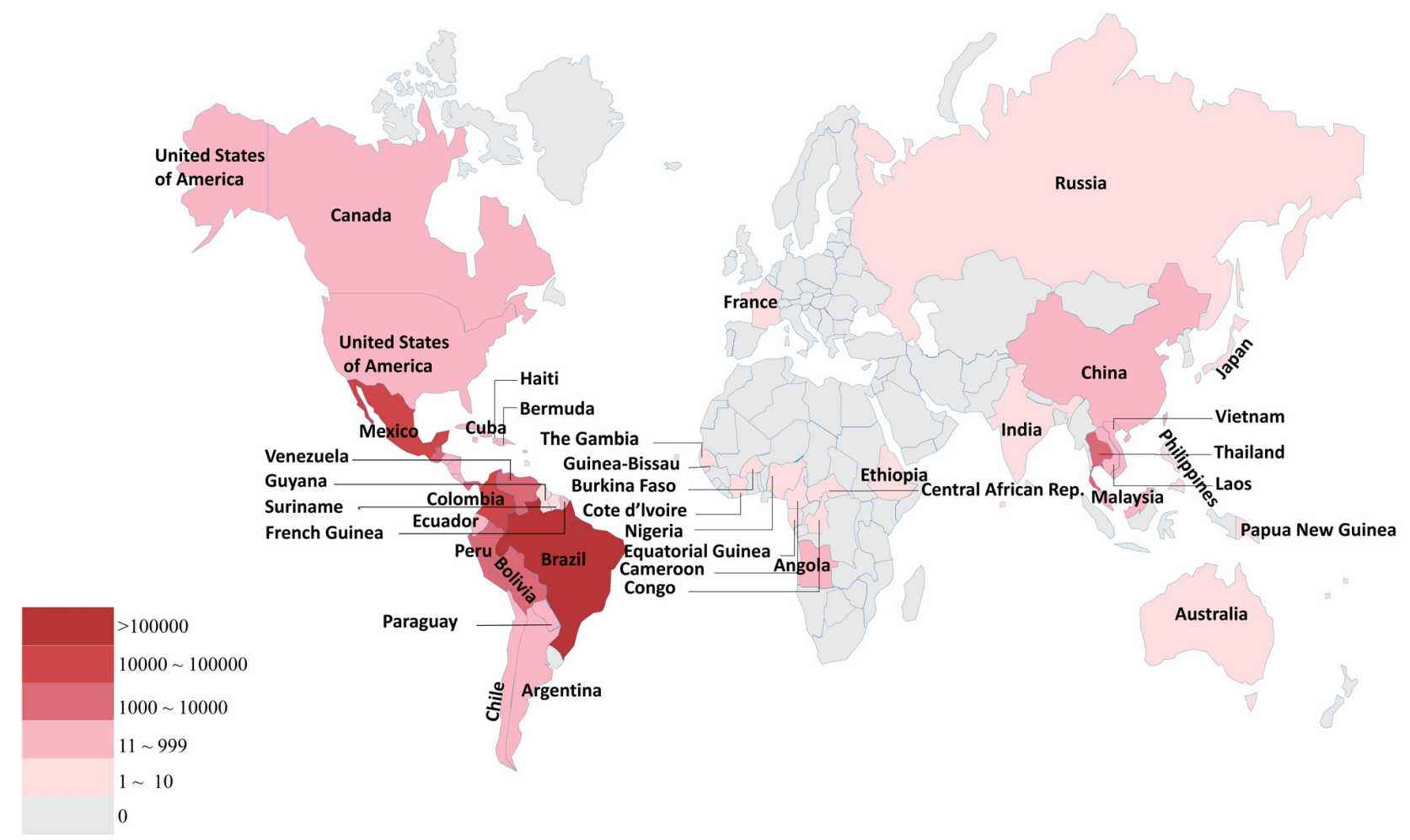

FIGURE 1 | Summary of ZIKV morbidity statistics with country- and quarter-level panel data. The deeper the color, the higher the number of infected people.

specific receptors on host cells, such as DC-SIGN, AXL, Tyro, and TIM-1 (Musso and Gubler, 2016; Nowakowski et al., 2016; Meertens et al., 2017). Several proteins, including DC-SIGN and TIM as well as some TAM proteins that belong to the phosphatidylserine receptor family, have been reported to act as receptors for entry of dengue virus (DENV)(Lozach et al., 2005; Meertens et al., 2012; Perera-Lecoin et al., 2013). To determine whether these receptors are also involved in ZIKV entry, a series of transfected HEK293T cells expressing DC-SIGN, TIM1, or a TAM family member (AXL or Tyro3) could be infected by ZIKV at varying degrees (Hamel et al., 2015). DC-SIGN consists of group II (calcium-dependent with single carbohydrate recognition domain) transmembrane C-type lectins that can interact through their carbohydrate recognition domains to bind carbohydrates to viral protein E (Zelensky and Gready, 2005; Cruz-Oliveira et al., 2015). DC-SIGN also plays an important role in flavivirus binding and the infection of myeloid cells (NavarroSanchez et al., 2003) as it mediates attachment of viral particles on the cell surface and facilitates their interaction with primary receptors on the host cell (Chen et al., 1997; Germi et al., 2002). Tyro3 and AXL belong to the TAM family, a group of three receptor protein tryrosine kinases that mediate the clearance of apoptotic cells (Lemke and Rothlin, 2008). AXL is expressed in astrocytes and microglia in the human brain development and mediates ZIKV infection of glial cells (Nowakowski et al., 2016; Meertens et al., 2017). AXL consisting of two different Gas6binding epitopes, including the $\mathrm{N}$-terminal Ig-like domain, and a second Ig domain exists in the dimeric form. Gas6, which is the ligand of AXL, connects ZIKV to glial cells. TIM-1, which is abundant on Th-2 T cells, mucosal epithelial cells, and mast cells, mediates the attachment of ZIKV particles on the cell surface to facilitate their interaction with AXL as well as the subsequent infection (Hamel et al., 2015). The availability of different entry receptors is likely to provide an evolutionary advantage for the virus, and, as a result, the virus is able to infect a wide range of human host cells.

After binding with host cells, ZIKV is internalized by clathrin-mediated endocytosis and traffics to Rab5 ${ }^{+}$endosomes (Wang X. et al., 2017; Mottin et al., 2018). In the process of entering the host cell, AXL kinase activity is activated by the ZIKV/Gas6 complex, which downregulates interferon signaling and promotes infection. Then, the endosome membrane and virus envelope (E) are fused under the acidic environment of the endosome. The viral genomic RNA is then released into the cytoplasm (Wang X. et al., 2017; Mottin et al., 2018). In the process of virus entry, some inhibitors can block viral attachment, endocytosis, and fusion. The proteins $\mathrm{E}$ on ZIKV and the DC-SIGN, AXL, Tyro, and TIM-1 entry/adhesion factors on the host cell are involved in viral attachment, endocytosis, fusion, and entry (Hasan et al., 2017; Heinz and Stiasny, 2017; Shi and Gao, 2017). They all therefore serve as targets for the development of small molecule inhibitors. After virus entry, the genome of ZIKV is translated and cleaved into three structural proteins, including Capsid (C), Precursor of the 


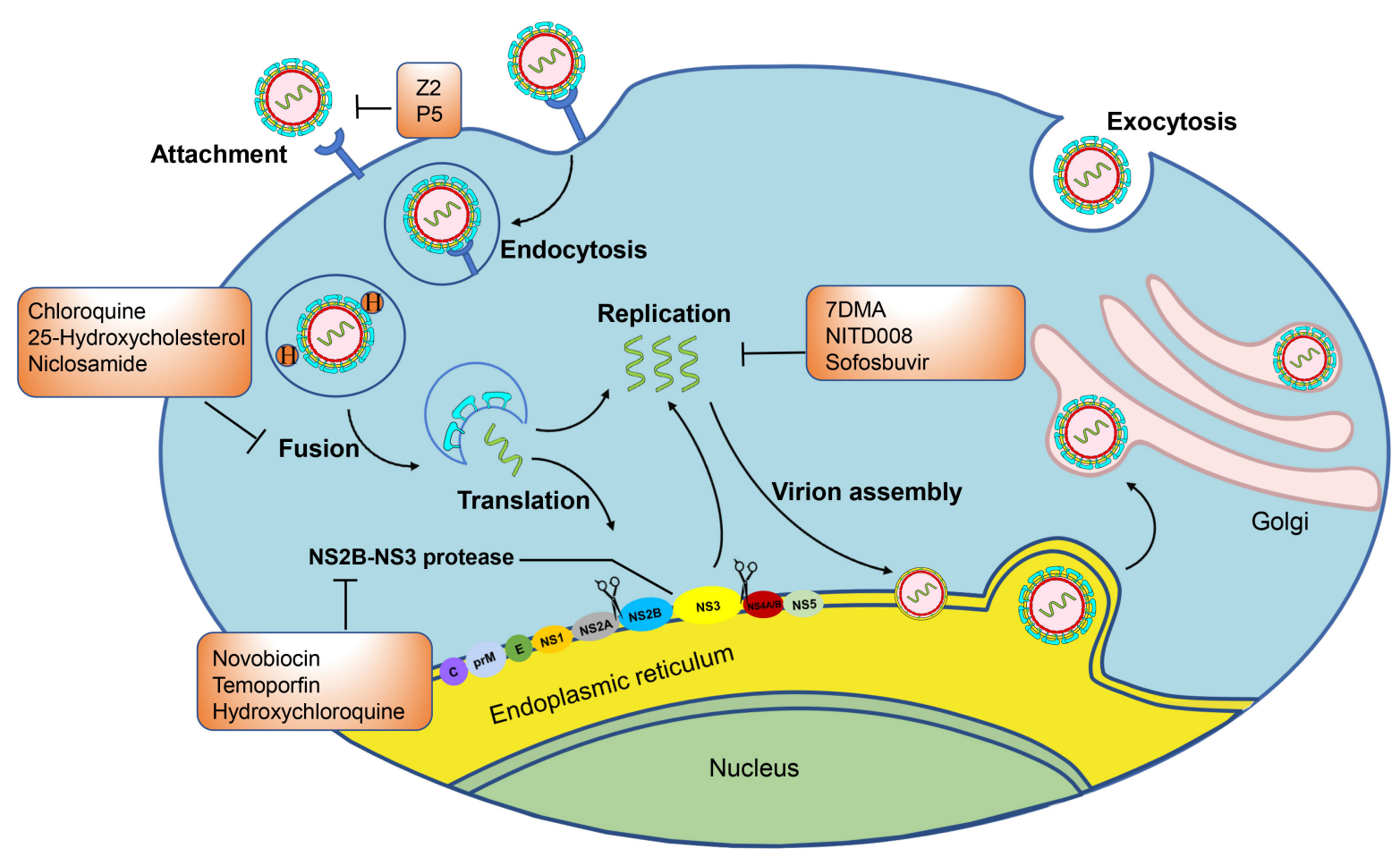

FIGURE 2 | Zika virus infectious life cycle: Host cell membrane receptors bind the E protein of the mature Zika virion, triggering endocytosis. The acidic environment of the endosome induces fusion of the host endosome membrane with the viral envelope and the release of the RNA genome. The RNA is translated into a polyprotein complex, which is cleaved by the host and viral proteases in the ER lumen and cytoplasm, respectively. Following translation, a replication complex is assembled and associated with virus induced membranes where viral replication takes place. The methylated (+) ssRNA, C, E, and prM proteins assemble to form immature virions in the endoplasmic reticulum (ER). The immature virions bud out of the ER into the Golgi apparatus, and they then mature in the trans-Golgi network that are released by exocytosis. In the orange boxes are the names of the compounds that can inhibit the marked steps of the virus lifecycle and that are evaluated in animal models or clinical trials.

membrane protein (prM)/membrane protein (M), Envelope (E), as well as seven non-structural proteins (NS1, NS2A, NS2B, NS3, NS4A, NS4B, and NS5). The NS1 protein is related to flavivirus replication and virion maturation. The NS2B protein activates the active region of the NS3 protein and forms an NS2B-NS3 complex with the NS3 protein to exert proteolytic enzyme activity. The NS4A and NS4B proteins comprise the endoplasmic reticulum (ER)-associated replication complex. The NS5 protein contains the C-terminal RNA-dependent RNA polymerase domain and the N-terminal methyltransferase domain, which cooperate during the initiation and extension of RNA synthesis. In addition, the NS5 protein is the largest NS protein in molecular weight and the most highly conserved. Then RNA is replicated with the actions of NS1, NS2B-NS3 proteinase and NS3 helicase, NS5 methyltransferase, and NS5RdRp. Viruses encode their own essential proteases in the viral replication process, which can serve as targets for therapeutic intervention. The methylated (+) ssRNA, C, E, and prM proteins are assembled to form immature virions in the ER. Then, the ER vesicles transport the virus particles to Golgi apparatus, and the virus particles undergo surface polysaccharide modification, prME protein trimer rearrangement, and Furin protease cleavage prM while mature virus particles with a smooth surface are produced, finally leaving the host cell by exocytosis as mature virus (Figure 2; Wang X. et al., 2017; Mottin et al., 2018). Some small molecule inhibitors that target the $\mathrm{C}$ protein or inhibit viral capsid formation are able to affect viral assembly and release. Meanwhile, correct expression and processing of nascent proteins in host cells are essential for efficient viral replication. Several host proteins, such as ER membrane complex, $\alpha$-glucosidase, cyclophilin, and proteasome elements, are responsible for monitoring proper protein synthesis, folding, and degradation. Impairment of these functions results in reduced viral assembly and budding. Therefore, these host proteins may also serve as targets for the development of small molecule ZIKV inhibitors.

Most antiviral drugs are small-molecule inhibitors that target different stages of the viral life cycle by interacting with virus or host proteins critical for virus replication (De Clercq and Li, 2016). For example, inhibiting AXL function can protect cells from infection and, thus, may be a potential target for the production of entry inhibitors. However, destroying AXL function may also have many adverse consequences (Nowakowski et al., 2016). In addition, the proteases crucial for ZIKV replication are potential targets for developing ZIKV replication inhibitors. Therefore, more effective and appropriate targets need to be developed by researchers. 


\section{CURRENT SMALL-MOLECULE INHIBITORS AGAINST ZIKV INFECTION AND THEIR MECHANISMS OF ACTION}

\section{ZIKV Entry Inhibitors}

\section{ZIKV Inhibitors Targeting Viral E Protein}

The structure of ZIKV envelope protein (E protein) is similar to that of other flaviviruses, and it has three characteristic domains: a central $\beta$-barrel-shaped domain I, a Slender fingerlike domain II, and a C-terminal immunoglobulin-like domain III (Dai et al., 2016). The recognition and binding of ZIKV E proteins to host cell receptors mark the beginning of ZIKV infection; therefore, some inhibitors designed for envelope proteins can effectively inhibit virus infection (Byrd et al., 2013).

Small molecule inhibitors that specifically target the ZIKV E protein have been reported. Peptide Z2 (Table 1), derived from the stem region of the ZIKV E protein, inhibits vertical transmission of ZIKV in pregnant C57BL/6 mice and protects type I or type I/II interferon receptor-deficient mice against lethal ZIKV challenge (Yu et al., 2017). Peptide Z2 can interact with viral $\mathrm{E}$ proteins to form a membrane pore and disrupt the integrity of the viral membrane (Yu et al., 2017). ZINC33683341 [Figure 3(1); Fernando et al., 2016], which can bind with the ZIKV E protein, is preferential when compared with glycan and can block the formation of glycoside bonds between ZIKV and host Vero cells at the concentration of $100 \mu \mathrm{M}$ (Table 2; Fernando et al., 2016).

Some small molecule inhibitors that non-specifically target the ZIKV E protein were also active against other medically relevant viruses that use a similar route of entry. P5, a peptide extracted from the stem of Japanese encephalitis virus E protein, can inhibit ZIKV entry into host cells by changing the conformation of the $\mathrm{E}$ protein under low $\mathrm{pH}$. The hydrophobicity of the last seven amino acid residues is also considered to be the key to the binding of the viral membrane (Table 1; Chen et al., 2017). In vivo experiments in mice highly sensitive to ZIKV showed that P5 can inhibit spermatic tubule disorder and reproductive epithelial cell degeneration while also alleviating the circulatory constriction of blood vessels (Chen et al., 2017).

The molecular tweezer CLR01, which has potent inhibition activity to envelope viruses, can inhibit ZIKV strains in Vero E6 cells [Figure 3(2) and Table 2] by destroying the intact membrane structure that is enriched with high levels of sphingolipid and cholesterol (Bavari et al., 2002; Chazal and Gerlier, 2003; Brugger et al., 2006; Lorizate et al., 2013; Rocker et al., 2018). In addition, it can inhibit ZIKV infection in semen, urine, saliva, cerebrospinal fluid, and other body fluids, but lose activity in serum (Rocker et al., 2018). Some studies have attributed this effect to the relatively high protein content in serum (Rocker et al., 2018).

Baicalin [Figure 3(3)], which has high affinity to the virus E protein and low toxicity to cells, can inhibit ZIKV from entering cells (Table 2; Oo et al., 2019). (-)-Epigallocatechin gallate (EGCG), a polyphenol from green tea, was shown to inhibit many viruses [Figure 3(4) and Table 2; Isaacs et al., 2008; Nance et al., 2009; Calland et al., 2012]. Accordingly, EGCG can bind to the ZIKV E protein to block ZIKV entry into host cells (Song et al., 2005). However, EGCG contains the catechol group that may non-specifically inhibit many different targets (Mottin et al., 2018). Curcumin can inhibit ZIKV infection in a dosedependent manner [Figure 3(5)]. It is not only a replication inhibitor of ZIKV, but also prevents the viral E protein from

TABLE 1 | Zika virus peptide inhibitors.

\begin{tabular}{|c|c|c|c|c|c|c|}
\hline Inhibitor & Sequence & Testing model & Cell lines & $\mathrm{IC}_{50}(\mu \mathrm{M})$ & $\mathrm{CC}_{50}(\mu \mathrm{M})$ & References \\
\hline \multirow[t]{3}{*}{ Peptide Z2 } & MAVLGDTAWDF & in vitro & BHK21 cells & $1.75 \pm 0.13$ & - & Yu et al. (2017) \\
\hline & GSVGGALNSLG & & & $3.69 \pm 0.27$ & & \\
\hline & KGIHQIFGAAF & & Vero cells & & & \\
\hline \multirow[t]{2}{*}{ P5 } & GQASNGVFVIH & in vitro & Vero cells & 3.27 & - & Chen et al. (2017) \\
\hline & WGKFDSFGIAV & & & & & \\
\hline \multirow[t]{6}{*}{ Ev37 } & GLINEKKVQQYLDE & in vitro & Huh-7 cells & - & - & Li et al. (2019) \\
\hline & KLPNGWKGALKSL & & & & & \\
\hline & VHKAAKNQNLCAF & & & & & \\
\hline & NVDTVGMCDADCK & & & & & \\
\hline & RQGKAKGVCHGT & & & & & \\
\hline & KCKCDVELSYKK & & & & & \\
\hline Aprotinin & - & in vitro & - & $0.07 \pm 0.012$ & - & Shiryaev et al. (2017) \\
\hline Acyl-KR-aldehyde & - & - & - & 0.208 & - & Li et al. (2017d) \\
\hline \multirow[t]{2}{*}{ AH-D peptide } & SGSWLRDWWDWIC & in vivo & In mouse & 0.0119 & - & $\begin{array}{l}\text { Cho et al. (2009), } \\
\text { Jackman et al. (2018) }\end{array}$ \\
\hline & TVLTDFKTWLQSKL & & & & & \\
\hline FFAAP & FFAAP & in vitro & $\begin{array}{l}\text { Human JEG-3 cells } \\
\text { Vero cells }\end{array}$ & & - & $\begin{array}{l}\text { Margueron and } \\
\text { Reinberg (2011), Di } \\
\text { Croce and Helin (2013), } \\
\text { Kim et al. (2015), } \\
\text { Vasireddi et al. (2019) }\end{array}$ \\
\hline ZMP STE24 & - & in vitro & T98-G cells & - & - & Fu et al. (2017) \\
\hline
\end{tabular}


binding to the cell surface (Mounce et al., 2017; Roy et al., 2017). In Vero cells, the $\mathrm{IC}_{50}$ and $\mathrm{CC}_{50}$ value of curcumin inhibiting ZIKV is 1.90 and $11.6 \mu \mathrm{M}$, respectively (Table 2; Mounce et al., 2017). Nanchangmycin [Figure 3(6)], produced by Streptomyces nanchang fermentation, can inhibit gram-positive bacteria and has insecticidal and antibacterial activities against poultry in vitro (Rausch et al., 2017). For Zika virus, Nanchangmycin can inhibit ZIKV infection by blocking clathrin-mediated endocytosis with $\mathrm{IC}_{50}$ s between 0.1 and $0.4 \mu \mathrm{M}$, and it has low toxicity in this range (Table 2) in human U2OS cells, human brain microvascular endothelial cells (HBMEC), and human Jeg-3 cells, respectively (Rausch et al., 2017).

\section{ZIKV Inhibitors Targeting Endosome}

Endosomes provide a transport route for ZIKV to enter host cells. Ev37 (Table 1), an endosomal scorpion peptide inhibitor, can effectively inhibit ZIKV infection at a non-cytotoxic concentration ( $\mathrm{Li}$ et al., 2019). Ev37 is a broad-spectrum and specific antiviral peptide, which can alkalize the $\mathrm{pH}$ value of endosomes, inhibit the release of a viral genome, and prevent it from entering the cytoplasm, thus blocking ZIKV infection (Li et al., 2019). In Huh-7 cells, Ev37 can reduce $87 \%$ of ZIKV infection at a concentration of $10 \mu \mathrm{M}$ (Li et al., 2019). Chloroquine (Li et al., 2017a), Suramin (Albulescu et al., 2017), and 25-hydroxycholesterol [Figure 3(7-9) and Table 2; Li et al., 2017a) demonstrated their ability to inhibit ZIKV internalization in vitro. Niclosamide is an FDA-approved drug broadly used in the treatment of intestinal helminthiasis [Figure 3(10) and Table 2]. It can prevent endosomal acidification, but the mechanism is not fully elucidated (Fonseca et al., 2012; Jurgeit et al., 2012).

\section{ZIKV Inhibitors Targeting AXL}

AXL is a tyrosine kinase receptor (TKR), which can mediate viral attachment to host cells. Therefore, it is necessary to inhibit primary cells with high AXL content (Nowakowski et al., 2016). Cabozantinib and BMS-777607 are two kinase inhibitors that inhibit AXL [Figure 3(11,12); Rausch et al., 2017]. In human $\mathrm{U} 2 \mathrm{OS}$ cells, their $\mathrm{IC}_{50}$ values are 0.2 and $0.6 \mu \mathrm{M}$, respectively, and the $\mathrm{CC}_{50}$ values are greater than $10 \mu \mathrm{M}$ (Table 2; Rausch et al., 2017). However, the experiments showed that AXL inhibitors were effective only on AXL-rich cells (Rausch et al., 2017), indicating that the effect is cell-type specific.

Although several studies proclaimed that AXL is a receptor for ZIKV entry in vitro, a few reports showed the opposite results. The genetic ablation of AXL has no significant effect on ZIKV entry or ZIKV-mediated cell death in human-induced pluripotent stem cell (iPSC)-derived NPCs or cerebral organoids (Nyboe Andersen et al., 2017; Rausch et al., 2017) reported that Jeg-3 cells that show no detectable AXL expression were highly permissive to ZIKV infection, suggesting that AXL may not be essential for ZIKV infection. This hypothesis is corroborated by an in vivo study (Wang Z. Y. et al., 2017). Notably, the AXL receptor supports neural stem cell survival, proliferation and neurogenesis (Ji et al., 2014), and signaling; the AXL also regulates blood-brain barrier (BBB) integrity in the context of viral infections (Miner et al., 2015). Therefore, while blocking AXL may protect against ZIKV infecting or viral replication, perturbation of AXL function may also have multiple adverse consequences. Therefore, the use of the AXL receptor as an idea target for the inhibition of Zika virus infection remains to be confirmed. Efforts to elucidate the molecular mechanism for ZIKV infection, through both targeted TAM receptor knockout studies and unbiased screening for other binding factors that render cells resistant to ZIKV, will lead to the identification of new targets for development of anti-ZIKV therapeutics.

\section{ZIKV Replication Inhibitors ZIKV Inhibitors Targeting NS2B-NS3 Protease}

NS2B-NS3 protease of Zika virus plays an essential role in ZIKV replication and maturation. NS2B-NS3 processes the viral nonstructural proteins from the viral polyprotein into individual proteins. NS2B-NS3 is a serine protease that consists of the N-terminal domain of NS3 and a short cofactor from the hydrophilic core sequence of NS2B. Like the NS4A cofactor of the HCV protease, Flavivirus NS3 is inactive without the NS2B co-factor (Erbel et al., 2006).

Three different ZIKV NS2B-NS3 protease (ZIKVpro) constructs have been proposed. First, a covalent $\mathrm{G}_{4} \mathrm{SG}_{4}$ linker peptide between NS2B and NS3 (gZiPro) construct was adopted based on previous West Nile and DENV protease constructs (Lei et al., 2016). The other two constructs include one bivalent protease consisting of two separate polypeptide NS2B and NS3 (bZiPro) (Zhang et al., 2016) and one with its own NS2B C-terminal peptide (TGKR) binding NS2B to NS3 (eZiPro) (Phoo et al., 2016). Remarkably, the single-chain enzyme gZiPro with an artificial linker that is commonly applied for the constructs of other flaviviruses has been widely used for screening inhibitors. Aprotinin, a 58 amino acid bovine trypsin inhibitor, inhibits ZIKV NS2B-NS3 protease with an $\mathrm{IC}_{50}$ of $70 \mathrm{nM}$ by blocking the interactions of NS3 and NS2B, as predicted by molecular modeling studies (Table 1; Shiryaev et al., 2017). By using structure-based virtual screening, novobiocin and lopinavir-ritonavir can inhibit ZIKV NS2B-NS3 protease activity by using molecular docking analysis [Figure 3(13-15); Yuan et al., 2017]. Novobiocin, an aminocoumarin antibiotic, inhibited protease activity by highly stable binding with ZIKV NS2B-NS3 protease to diminish its catalytic efficiency (Kirby et al., 1956; Yuan et al., 2017). It can inhibit ZIKV replication with an $\mathrm{IC}_{50}$ of $26.12 \pm 0.33 \mu \mathrm{g} / \mathrm{ml}$ and $\mathrm{CC}_{50}$ of $850.50 \mu \mathrm{g} / \mathrm{ml}$ in Vero cells and an $\mathrm{IC}_{50}$ of $38.14 \pm 4.53 \mu \mathrm{g} / \mathrm{ml}$ and $\mathrm{CC}_{50}$ of $1103.18 \mu \mathrm{g} / \mathrm{ml}$ in Huh-7 cells (Table 3; Yuan et al., 2017). Lopinavir-ritonavir can inhibit protease activity of ZIKV replication with an $\mathrm{IC}_{50}$ of $4.78 \pm 0.41 \mu \mathrm{g} / \mathrm{ml}$ and $\mathrm{CC}_{50}$ of $30.00 \mu \mathrm{g} / \mathrm{ml}$ in Vero cells and an $\mathrm{IC}_{50}$ of $3.31 \pm 0.36 \mu \mathrm{g} / \mathrm{ml} \mathrm{CC}_{50}$ of $32.12 \mu \mathrm{g} / \mathrm{ml}$ in Huh-7 cells (Table 3; Yuan et al., 2017).

Recently, Phoo et al. have shown that the glycine-rich artificial linker or "TGKR" peptide could introduce steric hindrance, resulting in the change of the inhibitor-binding mechanism (Phoo et al., 2016). The wide-type NS2B and NS3pro domain are not covalently linked (Kim et al., 2013). bZiPro, which is closer to the native state, has higher activity and is more suitable 
Wang et al.

Small-Molecule Zika Virus Inhibitors

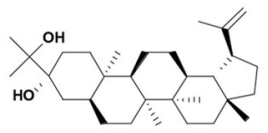

(1) ZINC33683341

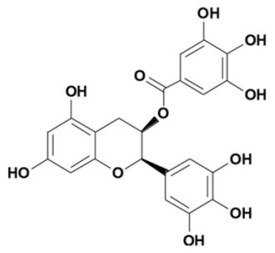

(4) EGCG

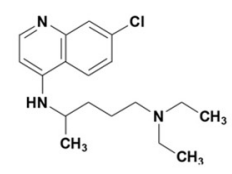

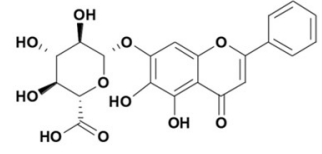

(2) Tweezer CLR01

(3) Baicalin

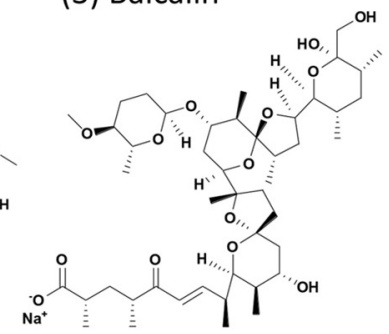

(6) Nanchangmycin

(5) Curcumin

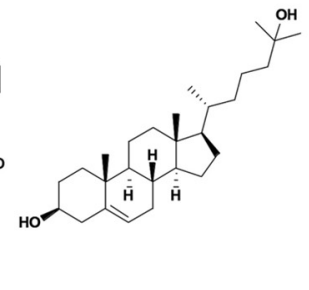

(7) Chloroquine

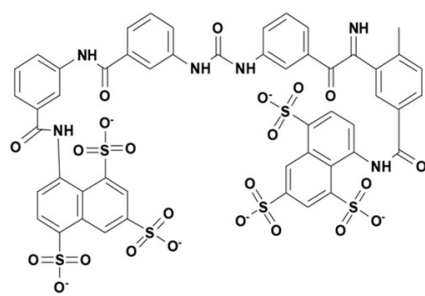

(8) Suramin

(9) 25-hydroxycholesterol
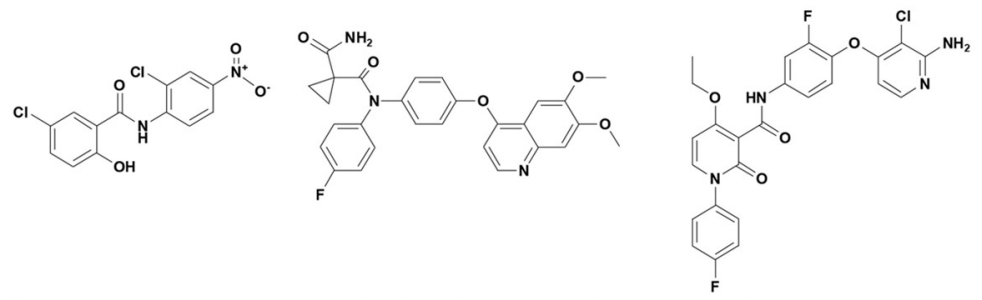

(10) Niclosamide

(11) Cabozantinib

(12) BMS-777607
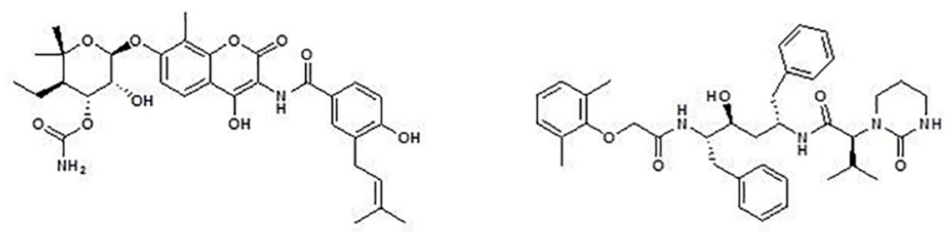

(13) Novobiocin

(14) Lopinavir
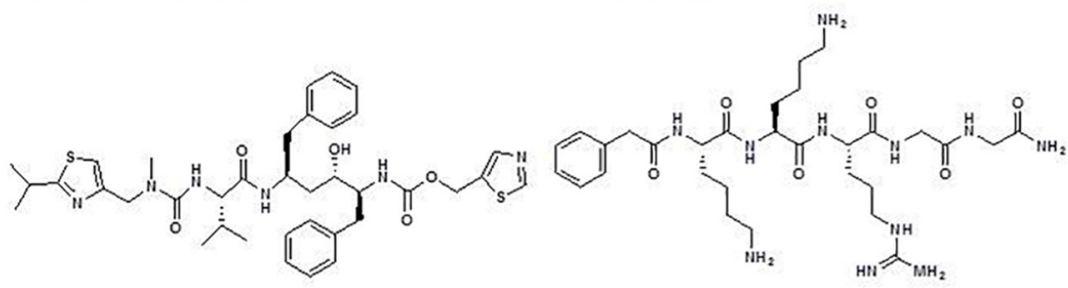

(15) Ritonavir

(16) Phenylacetyl-LysLys- Arg-Gly-Gly- $\mathrm{NH}_{2}$

FIGURE 3 | Continued

Frontiers in Microbiology | www.frontiersin.org

6

December 2019 | Volume 10 | Article 2725 
<smiles>NCCCCC[C@H](NC(=O)Cc1ccccc1)C(=O)N[C@@H](CCCCN)C(=O)N[C@@H](CCCCN)C(=O)O</smiles>

(17) 4-guanidinomethylphenylacetyl-Lys-Lys-Arg- $\mathrm{NH}_{2}$

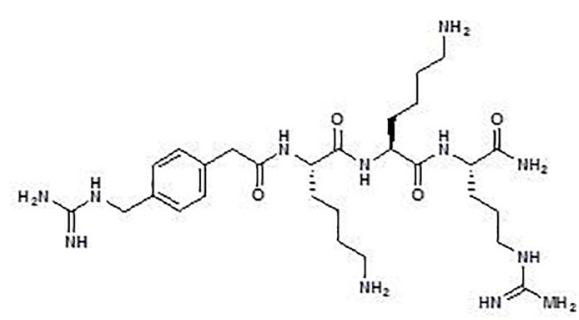

(18) 4-guanidinomethylphenylacetyl-Arg-Arg-Arg-4amidinobenzylamide<smiles></smiles>

(19) Hydrolysis product of phenylacetyl-Lys-Lys-Arg-Gly-Gly$\mathrm{NH}_{2}$

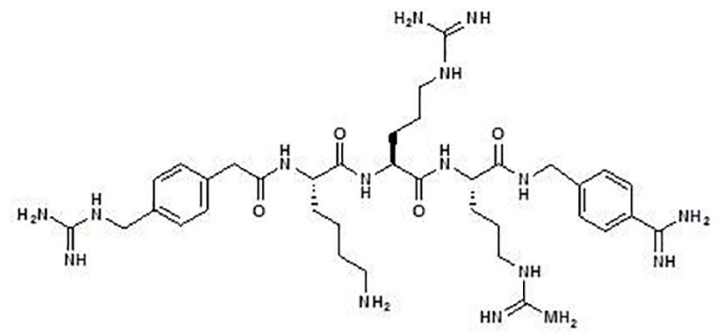

(20) Hydrolysis product of 4guanidinomethylphenylacetyl-Lys-Lys-Arg- $\mathrm{NH}_{2}$<smiles>N=C(N)NCCC[C@H](NC(=O)[C@H](Cc1ccc(CN)cc1)NC(=O)c1ccccc1)B(O)O</smiles><smiles>N=C(N)NCCC[C@H](NC(=O)[C@H](Cc1cccc(NC(=N)N)c1)NC(=O)c1ccccc1)B(O)O</smiles>

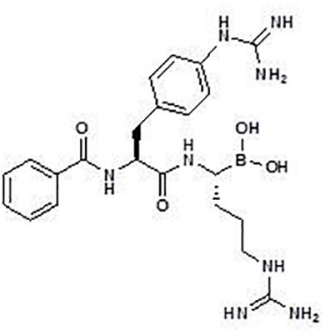

(23) $\mathrm{B}(\mathrm{OH})_{2} \mathrm{Bz}-(4-$

(22) $\mathrm{B}(\mathrm{OH}) 2 \mathrm{Bz}-(3-$ guanidinyl) Phe-Arg$\mathrm{B}(\mathrm{OH})_{2}$ 


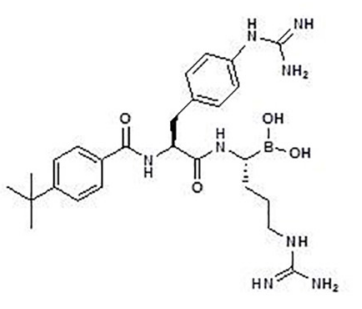

(24) 4-tBuBz-(4guanidinyl) Phe-Arg$\mathrm{B}(\mathrm{OH})_{2}$

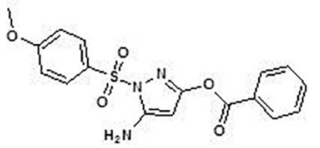

(25) 5-amino-1-((4methoxyphenyl)sulfo nyl)-1H-pyrazol-3-yl<smiles>CCN(CCO)CCCC[C@@H](c1ccccc1)c1cccc2cc(Cl)ccc12</smiles>

(26)Hydroxychloroquine (27) Myricetin<smiles>Cc1cc(-c2oc3cc(O)cc(O)c3c(=O)c2O)cc(O)c1O</smiles>

$\mathrm{OH}$<smiles>O=c1cc(-c2ccc(Cl)cc2)oc2cc(O)cc(O)c12</smiles>

(28) Apigenin<smiles>COc1cc(-c2oc3cc(O)cc(O)c3c(=O)c2O)ccc1O</smiles>

(29) Isorhamnetin<smiles>Cc1ccc(C2C3=C(O)CC(C)(C)C[C@]3(C)Nc3ccccc3N2CC(=O)NCCc2cnc[nH]2)cc1</smiles>

(32) BAS 19192837<smiles>Cc1ccc(-c2cc(=O)c3c(O)cc(O)cc3o2)cc1O</smiles>

(35) Luteolin<smiles>O=C(O)C1Cc2c(O)cc(O)cc2O[C@H]1c1cc(O)c(O)c(O)c1</smiles>

(38) Epigallocatechin gallate

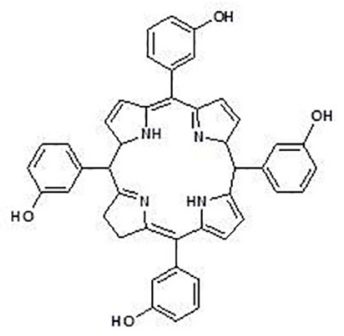

(30) Temoporfin<smiles>COc1ccc2cc3c(cc2c1OC)CCc1cc2c(cc1-3)OCO2</smiles>

(33) Berberine<smiles>Cc1cc(O)cc2oc(-c3ccc(O)cc3)c(O[C@H]3OC(CO)[C@@H](O)[C@H](O)[C@H]3O)c(=O)c12</smiles>

(36) Astragalin<smiles>O=C(O)c1cc(O)c(O)c(O)c1</smiles>

(39) Gallocatechin gallate<smiles>CC(=O)Oc1ccccc1C(=O)Nc1ncc([N+](=O)[O-])s1</smiles>

(31) Nitazoxanide

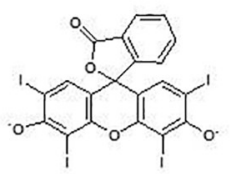

(34) Erythrosin B<smiles>COc1ccc(-c2oc3cc(O)cc(O)c3c(=O)c2O[C@H]2O[C@H](C)[C@@H](O)[C@H](O)[C@H]2O)cc1O</smiles>

(37) Rutin<smiles>NCc1ccccc1CNc1ncn[nH]1</smiles>

(40) ZINC64717952 


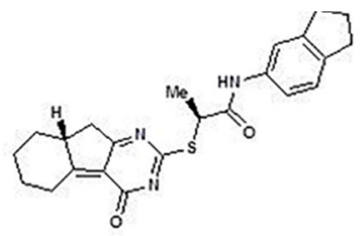

(41) ZINC39563464<smiles>CC1=C(/C=C/C(C)=C/C=C/C(C)=C/C(=O)Nc2ccc(O)cc2)C(C)(C)CCC1</smiles>

(44) N-(4-hydroxyphenyl) (45) 7DMA retinamide<smiles>O=c1cc(-c2ccccc2)oc2cc(O)c(O)c(O)c12</smiles>

(42) Baicalein

(43) DMB213

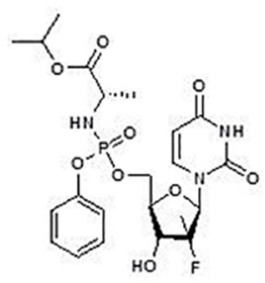

(46) Sofosbuvir

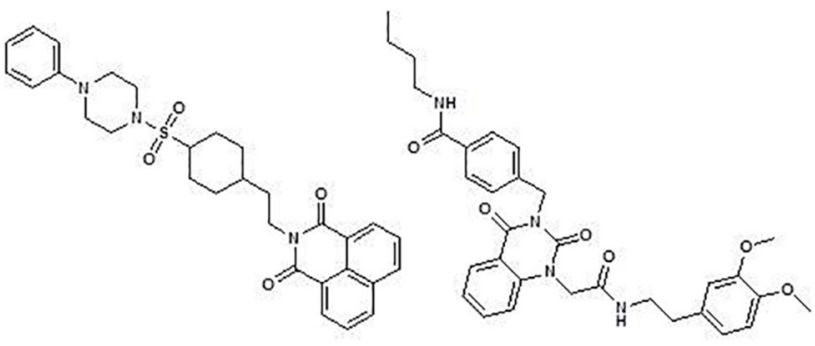<smiles>Cc1ccc2c(c1)C(=O)C(C(=O)c1ccccc1)CN2CC(=O)[C@H](C)c1ccccc1</smiles>

(47) F3043-0013

(48) F0922-0796

(49) F1609-0442

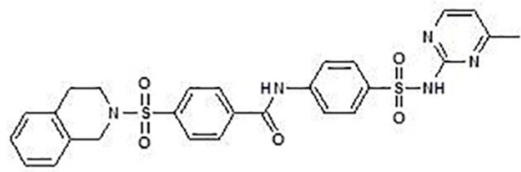<smiles>C[C@H](NC(=O)c1cccc(O)c1)c1cccc2c1CCC2</smiles>

(50) F1750-0048

(51) ZINC50166190

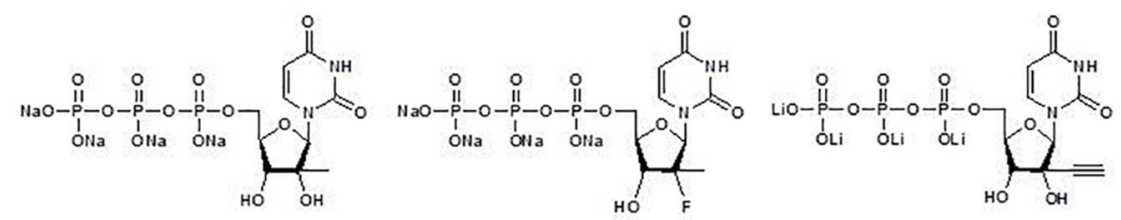

(52) 2'-C-Me-UTP

(53) 2'-F-2'-C-

Me-UTP

(54) 2'-C-ethynyl-

UTP<smiles>COc1cc(NC(=O)Nc2cccc(CNC(=O)OC3CCOC3)c2)ccc1-c1cnco1</smiles><smiles></smiles>

(55) 3'-dUTP

(56) Merimepodib

(57) Resiquimod 


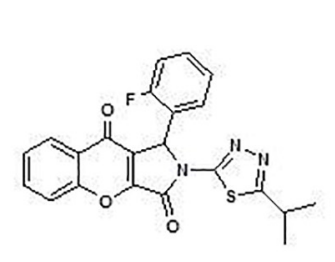<smiles>Cc1cc(C)c(CNC(=O)c2cc(-c3ccc(N4CCN(C)CC4)nc3)cc3c2cnn3C(C)C)c(=O)[nH]1</smiles><smiles>CC(=O)c1nc(F)c[nH]c1=O</smiles>

(58) AV-C

(59) GSK926

(60) T-705
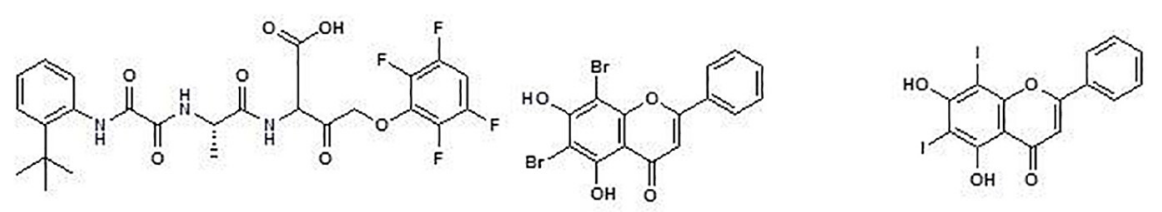

(61) Emricasan

(62) FV13

(63) FV14<smiles>O=C(c1cc(Cl)cc(Cl)c1O)c1[nH]c(F)c(Br)c1Br</smiles><smiles>CS(=O)(=O)Nc1ccc(Cc2noc(-c3ccc4c(c3)C(CCCN)C=C4)n2)cc1</smiles>

(64) Compound 1

(65) PKI 14-22<smiles></smiles>

(66) Cavinafungin<smiles>COC(=O)C1=C(C)NC(C)=C(C(=O)OC2CCCN(Cc3ccccc3)C2)C1c1cccc(C(=O)O)c1</smiles>

(67) benidipine hydrochloride

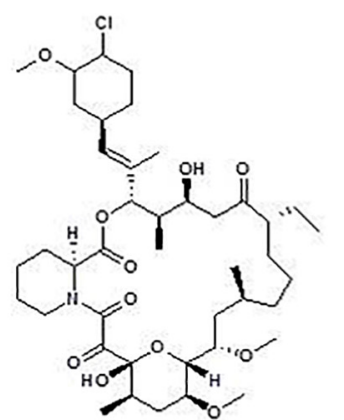

(68) Pimecrolimus<smiles>Cc1c(O)cccc1C(=O)N[C@H](CSc1ccccc1)[C@@H](O)CN1C[C@H]2CCCC[C@H]2CC1C(=O)C(C)(C)C</smiles>

(69) nelfinavir mesylate 


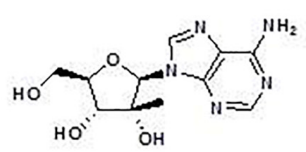

(70) 2'-CMA

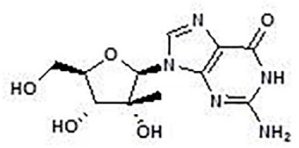

(73) 2'-CMG<smiles>CC(Cc1ccc(O)c(O)c1)C(C)Cc1ccc(O)c(O)c1</smiles>

(76) NDGA

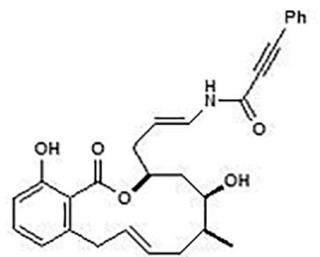

(79) SaliPhe<smiles>C[C@]1(O)[C@@H](O)[C@@H](CO)O[C@H]1n1ccc2c(N)ncnc21</smiles><smiles>C[C@]1(O)[C@@H](O)[C@@H](CO)O[C@H]1n1ccc(N)nc1=O</smiles>

\section{(71) 7-deaza-2'-CMA}

(72) $2^{\prime}-\mathrm{CMC}$<smiles>C[C@]1(O)[C@@H](O)[C@@H](CO)O[C@H]1n1ccc(=O)[nH]c1=O</smiles>

(74) 2'-CMU<smiles>Cc1cnc(NC(=O)c2cc(S(=O)(=O)N(C)C)ccc2N2CCCC2)s1</smiles>

(75) NGI-1<smiles></smiles>

(78) Obatoclax
(77) M4N<smiles>Nc1ccn([C@@H]2O[C@H](CO)[C@@H](O)C2(F)F)c(=O)n1</smiles>

(80) gemcitabine

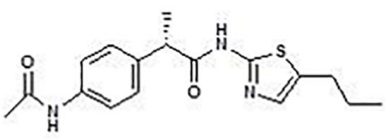

(81) PHA-690509

FIGURE 3 | Chemical structures of ZIKV small-molecule inhibitors.

for inhibitor screening than gZiPro and eZiPro because of its free active site being accessible to substrates or inhibitors (de la Cruz et al., 2011; Phoo et al., 2016; Shannon et al., 2016). Acyl-KR-aldehyde, a dipeptide, can form a covalent bond with the Ser135 residue of NS3 and the KR residues occupy the S1 and S2 sites of NS3 (Li et al., 2017d). Acyl-KR-aldehyde can inhibit the bZiPro construct of NS2B-NS3 protease with an $\mathrm{IC}_{50}$ of 208 nM (Table 1; Li et al., 2017d). Nuclear magnetic resonance (NMR) spectroscopy demonstrated that the bZiPro construct of NS2B-NS3 and Acyl-KR-aldehyde can form a stable complex (Li et al., 2017c). The peptidomimetic inhibitors composed of a $\mathrm{P} 1-\mathrm{P} 4$ segment and different $\mathrm{P} 1$ ' residues, including Phenylacetyl-Lys-Lys-Arg-Gly-Gly- $\mathrm{NH}_{2}$, 4-guanidinomethylphenylacetyl-Lys-Lys-Arg- $\mathrm{NH}_{2}$, 4-guanidinomethyl-phenylacetyl-Arg-Arg-Arg-4-amidinobenzylamide, a hydrolysis product of phenylacetyl-Lys-Lys-Arg-Gly-Gly-NH2, and a hydrolysis product of 4-guanidinomethyl-phenylacetyl-LysLys-Arg-NH2 [Figure 3(16-20)], can inhibit ZIKV replication against the NS2B-NS3 protease of ZIKV with an $\mathrm{IC}_{50}$ of $1.2 \pm 0.14,1.6 \pm 0.14,1.1 \pm 0.07 \mu \mathrm{M}$, and 18.4 \pm 1.9 $5.9 \pm 0.55 \mu \mathrm{M}$, respectively (Table 3; Phoo et al., 2018). As non-competitive inhibitors, five macrocyclic peptides can act as ligands with high affinity and can be rapidly isolated for nearly any target by using display screening approaches, such as an mRNA display or phage display (Passioura et al., 2014). These peptides can inhibit bZiPro constructs of NS2B-NS3 protease activity with an $\mathrm{IC}_{50}$ from 0.24 to $4.9 \mu \mathrm{M}$ (Nitsche et al., 2019). AH-D peptide, a 27-mer amphipathic $\alpha$-helical peptide, protects against lethal ZIKV infection with $\mathrm{IC}_{50}=0.012 \mu \mathrm{M}$ in primary neuronal cells, inhibits ZIKV infection in mouse brains, and preserves BBB integrity (Table 1; Cho et al., 2009; Jackman et al., 2018). The AH-D peptide also significantly reduced viral loads in the serum, brain, spleen, and optical nerve throughout the course of infection (Jackman et al., 2018). Four dipeptidic inhibitors have a C-terminal boronic acid moiety, including $\mathrm{Bz}-[4-(\mathrm{CH} 2 \mathrm{NH} 2)]$ Phe-Arg- $\mathrm{B}(\mathrm{OH})_{2}$, 
TABLE 2 | Zika virus entry inhibitors.

\begin{tabular}{|c|c|c|c|c|c|c|}
\hline $\begin{array}{l}\text { Number of } \\
\text { chemical } \\
\text { structures in } \\
\text { Figure } 3\end{array}$ & Inhibitor & $\begin{array}{l}\text { Testing } \\
\text { model }\end{array}$ & Cell lines & $\mathrm{IC}_{50}(\mu \mathrm{M})$ & $\mathrm{CC}_{50(\mu \mathrm{M})}$ & References \\
\hline 1 & Tweezer CLR01 & in vitro & Vero E6 cells & 8.2 & - & $\begin{array}{l}\text { Bavari et al. (2002), } \\
\text { Chazal and Gerlier } \\
\text { (2003), Brugger et al. } \\
\text { (2006), Lorizate et al. } \\
\text { (2013), Rocker et al. } \\
\text { (2018) }\end{array}$ \\
\hline 2 & ZINC33683341 & in vitro & Vero cells & - & - & Fernando et al. (2016) \\
\hline 3 & Baicalin & in vitro & Vero cells & 14 & 553 & Oo et al. (2019) \\
\hline 4 & EGCG & in vitro & Vero E6 cells & - & - & $\begin{array}{l}\text { Song et al. (2005), } \\
\text { Isaacs et al. (2008), } \\
\text { Nance et al. (2009), } \\
\text { Calland et al. (2012), } \\
\text { Carneiro et al. (2016) }\end{array}$ \\
\hline 5 & Curcumin & in vitro & Huh-7 cells & 1.90 & 11.6 & $\begin{array}{l}\text { Song and Ni (1998), } \\
\text { Mounce et al. (2017), } \\
\text { Nitsche et al. (2017), } \\
\text { Roy et al. (2017) }\end{array}$ \\
\hline \multirow[t]{3}{*}{6} & Nanchangmycin & in vitro & Human U2OS cells & 0.1 & 7 & $\begin{array}{l}\text { Liu et al. (2008), } \\
\text { Pierson and Kielian } \\
\text { (2013), Rausch et al. } \\
\text { (2017) }\end{array}$ \\
\hline & & & $\begin{array}{l}\text { Human HBMEC } \\
\text { cells }\end{array}$ & 0.4 & $>10$ & \\
\hline & & & Human JEG-3 cells & 0.97 & 6.10 & \\
\hline \multirow[t]{2}{*}{7} & Chloroquine & in vitro & Huh-7 cells & 1.72 & - & Li et al. (2017b) \\
\hline & & in vivo & $\begin{array}{l}\text { Vero cells; BALB/c } \\
\text { mice and A129 } \\
\text { mice }\end{array}$ & 4.15 & & \\
\hline 8 & Suramin & in vitro & Vero cells & 39.8 & 1900 & $\begin{array}{l}\text { Albulescu et al. (2017), } \\
\text { Coronado et al. (2018) }\end{array}$ \\
\hline 9 & 25-hydroxycholesterol & $\begin{array}{l}\text { in vitro } \\
\text { in vivo }\end{array}$ & $\begin{array}{l}\text { Vero cells; BALB/c } \\
\text { mice and A129 } \\
\text { mice }\end{array}$ & 0.188 & - & Li et al. (2017a) \\
\hline 10 & Niclosamide & in vitro & $\begin{array}{l}\text { A549 cells } \\
\text { SNB-19 cells }\end{array}$ & $\begin{array}{c}12.3 \pm 0.6 \\
1.72\end{array}$ & $4.8 \pm 1.0$ & $\begin{array}{l}\text { Baell and Holloway } \\
\text { (2010), Li et al. (2017d), } \\
\text { Xu et al. (2016), Li et al. } \\
\text { (2017d) }\end{array}$ \\
\hline 11 & Cabozantinib & in vitro & Human U2OS cells & 0.2 & $>10$ & Rausch et al. (2017) \\
\hline 12 & BMS-777607 & in vitro & Human U2OS cells & 0.6 & $>10$ & Rausch et al. (2017) \\
\hline
\end{tabular}

Bz-(3-guani-dinyl)Phe-Arg- $\mathrm{B}(\mathrm{OH})_{2}$, Bz-(4-guani-dinyl)Phe$\operatorname{Arg}-\mathrm{B}(\mathrm{OH})_{2}$, and 4-tBuBz-(4-guanidinyl)Phe-Arg- $\mathrm{B}(\mathrm{OH})_{2}$ [Figure 3(21-24)]. These compounds can inhibit ZIKV NS2BNS3 protease activity with $\mathrm{IC}_{50}$ from 0.25 to $2.1 \mu \mathrm{M}$ (Table 3; Nitsche et al., 2017).

$\mathrm{Li}$ Y. et al. have found that a pyrazole ester derivative, 5-amino1-((4-methoxyphenyl)sulfonyl) -1H-pyrazol-3-yl benzoate [Figure 3(25)], can inhibit ZIKV replication with an $\mathrm{IC}_{50}$ of $1.5 \mu \mathrm{M}$ when benzoyl-Nle-Lys-Arg-Arg-aminomethylcoumarin (BznKRR-AMC) was used as a substrate (Table 3; Li Y. et al., 2018). The benzoyl group of this inhibitor forms a covalent bond with the side chain of catalytic residue S135 to stabilize the closed conformation of the ZIKV bZiPro construct of NS2B-NS3 protease (Li Y. et al., 2018). In addition, a derivative of pyrazole ester, 5-amino-1-((4-methoxyphenyl)sulfonyl)-1H-pyrazol-3-yl benzoate, with an $\mathrm{IC}_{50}$ of $0.1 \mu \mathrm{M}$ can interact in a manner similar to the compound [Figure 3(25)] and strongly inhibit binary ZIKV bZiPro construct of NS2B-NS3 protease (Li Y. et al., 2018). Hydroxychloroquine [Figure 3(26)], a drug already approved and used in pregnancy, can inhibit the bZiPro construct of NS2B-NS3 protease activity with an inhibition constant (Ki) of $92.34 \pm 11.91 \mu \mathrm{M}$ (Table 3; Kumar et al., 2018).

Some natural products from edible plants, like myricetin, can inhibit ZIKV infection with an $\mathrm{IC}_{50}$ of $1.26 \mu \mathrm{M}$ and an inhibitory constant of ZIKV NS2B-NS3 protease activity with $K i$ of $0.77 \mu \mathrm{M}$ by establishing six hydrogen bonds with four Zika NS3pro residues: Lys73, Asn152, Gln74, and Gly124 [Figure 3(27) and Table 3; Roy et al., 2017]. Apigenin inhibits ZIKV infection with an $\mathrm{IC}_{50}$ of $56.32 \mu \mathrm{M}$ and inhibitory constant $K i$ of $34.02 \mu \mathrm{M}$ [Figure 3(28) and Table 3; Roy et al., 2017]. Isorhamnetin, also 
TABLE 3 | Zika virus replication inhibitors.

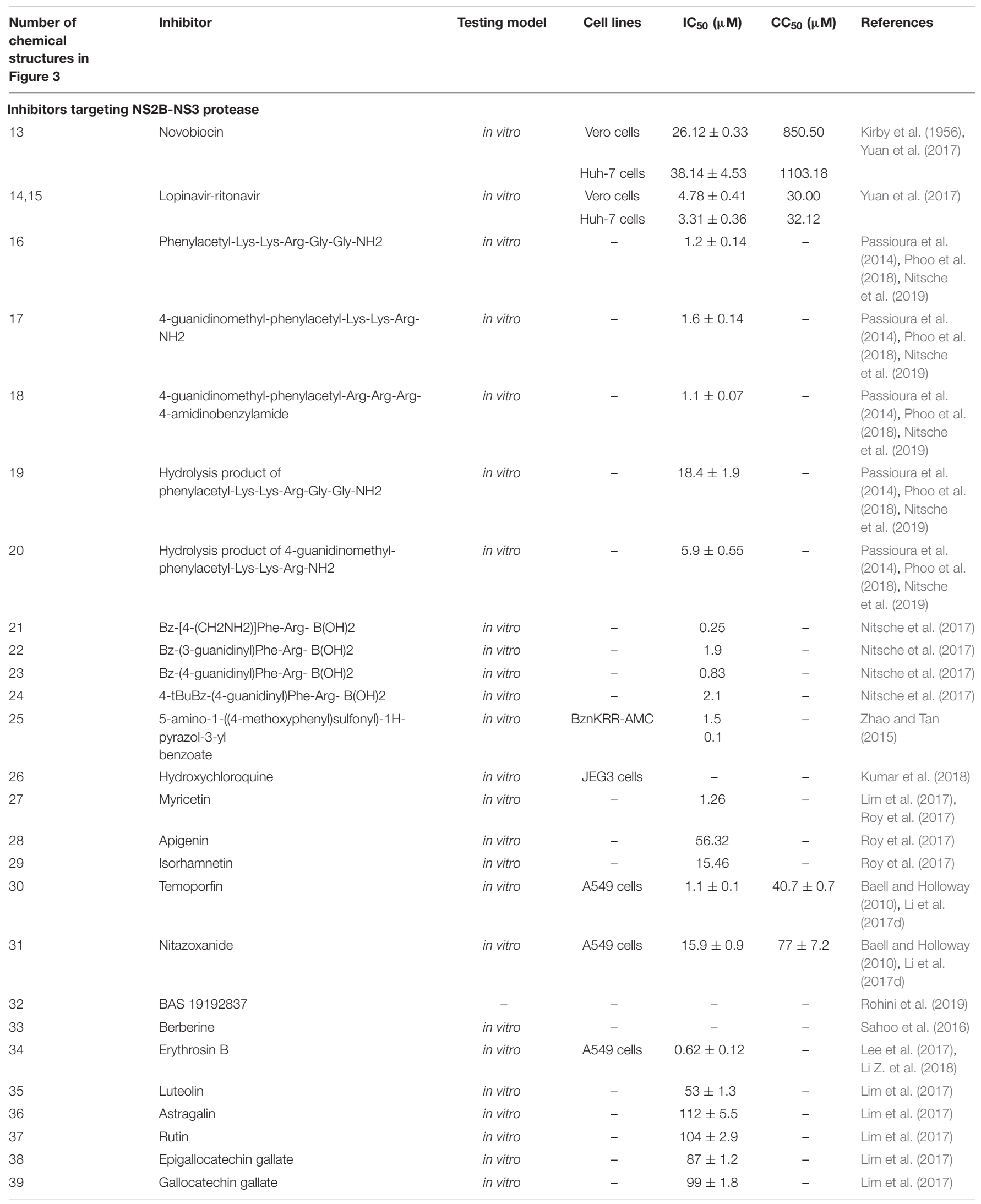


TABLE 3 | Continued

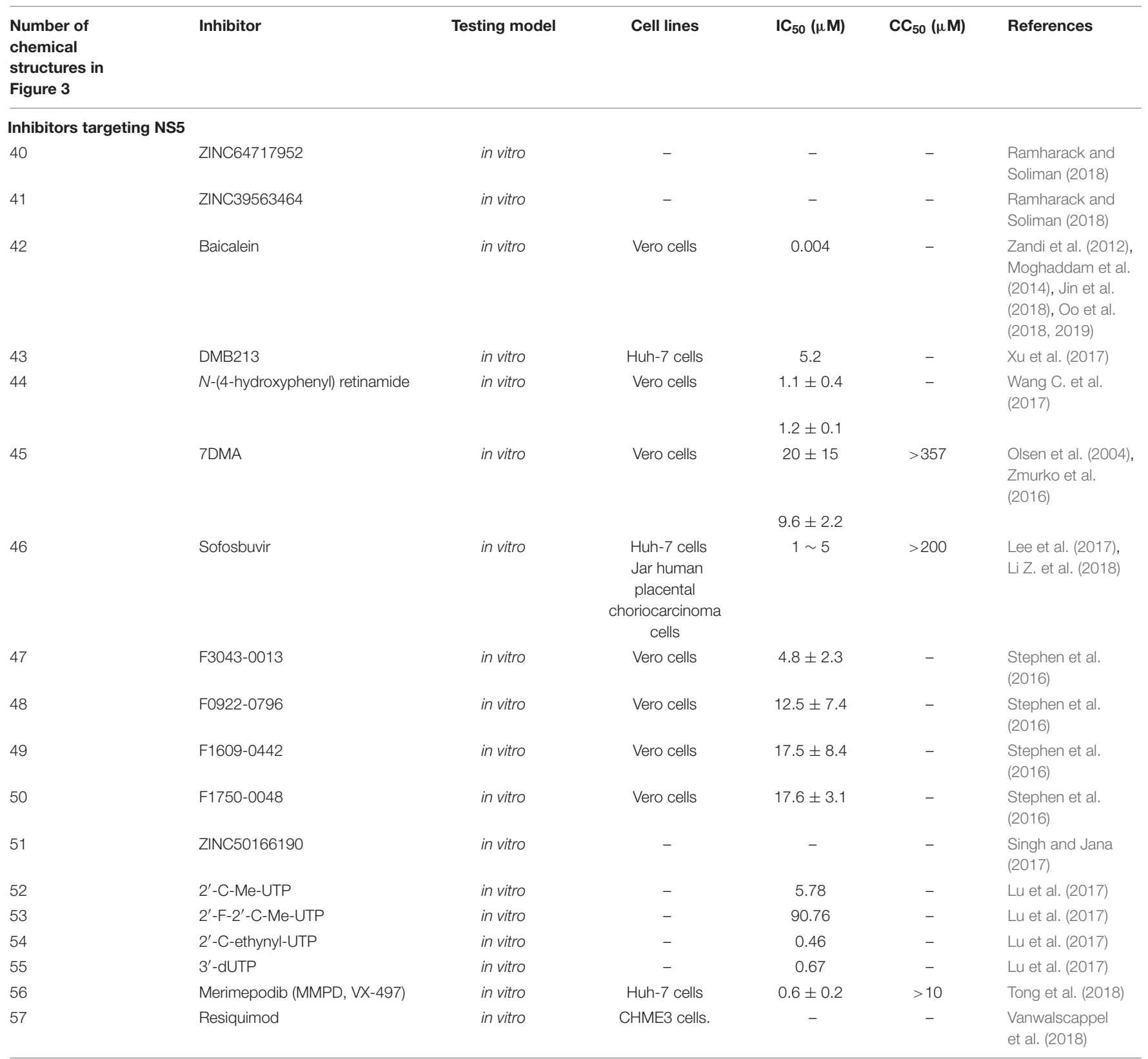

called 3 -Methylquercetin, can inhibit ZIKV infection with IC $_{50}$ of $15.46 \mu \mathrm{M}$ and $K i$ of $6.22 \mu \mathrm{M}$ as well as Quercetin with $\mathrm{IC}_{50}$ of $2.42 \mu \mathrm{M}$ and $K i$ of $1.12 \mu \mathrm{M}$ [Figure 3(29) and Table 3; Roy et al., 2017). Structurally, isorhamnetin is a derivative of quercetin with a very similar molecular structure (Roy et al., 2017). In addition, curcumin [Figure 3(5) and Table 2], a natural phenol with two aromatic rings linked by a heptadiene group, can inhibit ZIKV infection with $\mathrm{IC}_{50}$ of $3.45 \mu \mathrm{M}$ and $K i$ of $2.61 \mu \mathrm{M}$, most likely by having bivalent binding sites (Song and Ni, 1998; Roy et al., 2017). The introduction of a C-terminal boronic acid moiety into dipeptidic inhibitors can raise the affinity to target by a 1000-fold (Nitsche et al., 2017). However, curcumin, quercetin, and other flavonoids have shown themselves to be promiscuous inhibitors, e.g., via colloidal aggregation (McGovern et al., 2002; Duan et al., 2015; Tritsch et al., 2015). Curcumin also contains reactive Michael acceptors, and quercetin has a catechol, a wellknown PAINS substructure, which might make these compounds less favorable (Mottin et al., 2018).

A total of 2,816 approved and investigational drugs were screened using a high-throughput screening (HTS) assay (Li et al., 2017d). Among these, 23 compounds were confirmed to possess an $\mathrm{IC}_{50}$ below $15 \mu \mathrm{M}$. Three of them, including temoporfin, niclosamide, and nitazoxanide, could inhibit with an $\mathrm{IC}_{50}$ of $1.1 \pm 0.1,12.3 \pm 0.6,15.9 \pm 0.9 \mu \mathrm{M}$ and $\mathrm{CC}_{50}$ of $40.7 \pm 0.7,4.8 \pm 1.0,77 \pm 7.2 \mu \mathrm{M}$ in A549 cells, respectively [Figure 3(10,30,31) and Table 3; Baell and Holloway, 2010). 
Temoporfin was tested in a viremia mouse model and a lethal mouse model, and it was able to inhibit viremia and protect $83 \%$ of the mice; the mice that survived did not present any signs of neurological disorder ( $\mathrm{Li}$ et al., 2017d). These compounds inhibit the interaction between NS3 and the NS2B N-terminal fragment. By using an e-pharmacophore-based virtual screening assay, BAS 19192837 was chosen as a potent Zika NS2B-NS3 protein inhibitor [Figure 3(32)]. However, the experimental data of the $\mathrm{IC}_{50}$ about this inhibitor was not shown (Table 3; Rohini et al., 2019).

Berberine, an FDA-approved drug against DENV, has shown high binding affinity of $5.8 \mathrm{kcal} / \mathrm{mol}$, and it binds around the active site of the receptor [Figure 3(33) and Table 3; Sahoo et al., 2016]. Niclosamide, an FDA-approved category B anthelmintic drug for treating worm infections in both humans and domestic livestock, inhibited all three strains of ZIKV, which was measured by intracellular ZIKV RNA levels with $\mathrm{IC}_{50}$ values of $1.72 \mu \mathrm{M}$ in SNB-19 cells (Xu et al., 2016). PHA-690509, an investigational compound that functions as a cyclin-dependent kinase inhibitor (CDKi), inhibited three stains with $\mathrm{IC}_{50}$ values of $0.37 \mu \mathrm{M}$ as measured by intracellular ZIKV RNA levels in SNB-19 cells (Xu et al., 2016). According to experimental results, the mechanism of these two compounds occurs at post-entry stage, likely at the viral RNA replication step (Xu et al., 2016). Suramin [Figure 3(8)], an approved polyanion antiparasitic drug, can be a potential inhibitor of Zika virus complex NS2B/NS3 proteinase with $\mathrm{IC}_{50}$ of $47 \mu \mathrm{M}$ (Table 2; Coronado et al., 2018). Computational analysis showed that suramin suppressed NS2B/NS3 proteinase activity by blocking catalytical Ser135 residue and interacting with the catalytical histidine residue (Coronado et al., 2018). Erythrosin B [Figure 3(34)], a pregnancy category $\mathrm{B}$ food additive, inhibited ZIKV replication by targeting NS2B-NS3 proteases with an $\mathrm{IC}_{50}$ of $0.62 \pm 0.12 \mu \mathrm{M}$ in A549 cells (Table 3) via a non-competitive mechanism by enzymatic kinetic experiments (Li Z. et al., 2018). Erythrosin $\mathrm{B}$ can also inhibit ZIKV RNA synthesis and protein expression in ZIKV-relevant neural progenitor and human placental cells (Li Z. et al., 2018).

Two inhibitors were tested to inhibit NS2B-NS3 protease activity with $\mathrm{IC}_{50}$ values of 5.2 and $4.1 \mu \mathrm{M}$ by blocking the active site of ZIKV NS2B-NS3 protease in docked conformation (Lee et al., 2017). Five polyphenol compounds, including luteolin, astragalin, rutin, epigallocatechin gallate, and gallocatechin gallate from flavone and flavonol, inhibited ZIKV replication with $\mathrm{IC}_{50}$ values ranging from $22 \pm 0.2$ to $112 \pm 5.5 \mu \mathrm{M}$ [Figure 3(35-39) and Table 3; Lim et al., 2017].

\section{ZIKV Inhibitors Targeting NS5}

Zika virus NS5 is a relative conserved large protein among members of the genus, containing an MTase domain and an RNA polymerase (RdRp) domain connected by a 10 residues linker. ZIKV NS5 can be used as a template for genome replication with an efficiency similar to that of an RNA template (Lu et al., 2017). In one study, ZIKV NS5 could extend an RNA primer annealed to an RNA template in an $\mathrm{Mn}^{2+}$-dependent manner, as opposed to $\mathrm{Mg}^{2+}$ (Lu et al., 2017). ZINC64717952 and ZINC39563464 can interact with NS5 by enzyme-ligand interactions under virtual conditions to inhibit ZIKV propagation, but no clear data about $\mathrm{IC}_{50}$ and $\mathrm{CC}_{50}$ have been reported [Figure $3(40,41)$ and Table 3; Ramharack and Soliman, 2018].

Baicalein [Figure 3(42)], a flavonoid analog, could downregulate ZIKV replication up to $10 \mathrm{~h}$ post-infection, while prophylactic effects were evident in pretreated Vero cells with $\mathrm{IC}_{50} \approx 0.004 \mu \mathrm{M}$ and selectivity index $(\mathrm{SI}) \approx 105,000$ (Table 3; Oo et al., 2019). It also has antiviral activity against DENV, chikungunya virus (CHIKV), and influenza virus (Zandi et al., 2012; Moghaddam et al., 2014; Jin et al., 2018; Oo et al., 2018). DMB213 [Figure 3(43) and Table 3] is a pyridoxine-derived non-nucleoside small-molecule inhibitor with an $\mathrm{IC}_{50}$ of $5.2 \mu \mathrm{M}$ (Xu et al., 2017). This compound inhibits ZIKV by blocking RNA synthesis reactions catalyzed by recombinant ZIKV NS5 polymerase (Xu et al., 2017). A nuclear import inhibitor, $N$ (4-hydroxyphenyl) retinamide [Figure 3(44) and Table 3], can block the interaction between high nanomolar affinity ZIKV NS5 and the host cell importin $\alpha / \beta 1$ heterodimer (Wang S. et al., 2017). 7-deaza-2'-C-methyladenosine (7DMA) [Figure 3(45)], an inhibitor of hepatitis $\mathrm{C}$ virus polymerase (Olsen et al., 2004), could inhibit ZIKV strain MR766 with $\mathrm{CC}_{50}>357 \mu \mathrm{M}$ and an $\mathrm{IC}_{50}$ of $20 \pm 15 \mu \mathrm{M}$ in a CPE reduction assay and $9.6 \pm 2.2 \mu \mathrm{M}$ in a virus yield reduction assay in Vero cells (African Green monkey kidney cells; ECACC) (Table 3; Zmurko et al., 2016). In vivo, 7DMA also reduced viremia (between day 3 and 8 post infection) and delayed virus-induced morbidity and mortality in AG129 (IFN- $\alpha / \beta$ and IFN- $\gamma$ receptor knockout) mice infected with ZIKV (Zmurko et al., 2016). Sofosbuvir [Figure 3(46)], an FDA-approved nucleotide polymerase inhibitor, can efficiently inhibit replication and infection of several ZIKV strains, including African and American isolates, with $\mathrm{IC}_{50}$ values of 1-5 $\mu \mathrm{M}$ and $\mathrm{CC}_{50}>200 \mu \mathrm{M}$ in Huh-7 and Jar human placental choriocarcinoma cells (Table 3; Bullard-Feibelman et al., 2017). In addition, oral treatment with sofosbuvir also protected against ZIKV-induced death in 5-week-old C57BL/6J mice (Li Z. et al., 2018).

Using virtual screening, Stephen et al. identified four top-scoring ligands from the 28,341 compounds, including F3043-0013, F0922-0796, F1609-0442, and F1750-0048, against ZIKV with $\mathrm{IC}_{50}$ values of $4.8 \pm 2.3,12.5 \pm 7.4,17.5 \pm 8.4$, and $17.6 \pm 3.1 \mu \mathrm{M}$, respectively, by plaque reduction assay (PRA) [Table 3 and Figure 3(47-50); Stephen et al., 2016]. These compounds may cooperatively interact with the hydrophobic binding pocket, extending to the S-adenosyl homocysteine (SAH) binding pocket (Stephen et al., 2016). Based on the modeling of the catalytic domain of ZIKV RNA-dependent RNA polymerase (RdRpC), Ligand 6 [(S)-2-(3-hydroxyphenyl)-N(1,2,3,4-tetrahydronaphthalen-1yl)acetamide] (ZINC50166190) was chosen as potentially having inhibitory activity against ZIKV RdRpC protein by acting as a GTP-nucleotide analog to prevent initiation of ZIKV RNA polymerization [Figure 3(51) and Table 3; Singh and Jana, 2017). Some ribonucleotide $5^{\prime}$-triphosphate analogs like $2^{\prime}$-C-Me-UTP, 2'-F-2'-CMe-UTP, $2^{\prime}$-C-ethynyl-UTP, and $3^{\prime}$-dUTP inhibit ZIKV replication with $\mathrm{IC}_{50} \mathrm{~s}$ of $5.78,90.76,0.46$, and $0.67 \mu \mathrm{M}$ [Figure 3(52-55) and Table 3], respectively, as measured in the presence of $1 \mu \mathrm{M}$ competing UTP by an alternative non-radioactive 
coupled-enzyme assay ( $\mathrm{Lu}$ et al., 2017). One of the major inhibitory mechanisms of ribonucleotide $5^{\prime}$-triphosphate against ZIKV infection is its direct termination of viral RNA polymerases ( $\mathrm{Lu}$ et al., 2017). Merimepodib (MMPD, VX-497) [Figure 3(56)], a potent inhibitor of inosine- $5^{\prime}$ monophosphate dehydrogenase (IMPDH), inhibited ZIKV RNA replication with an $\mathrm{IC}_{50}$ of $0.6 \pm 0.2 \mu \mathrm{M}$ and $\mathrm{IC}_{90}$ of $1.0 \pm 0.2 \mu \mathrm{M}$ in Huh7 cells. In the cytotoxicity assay, the $\mathrm{CC}_{50}$ was determined to be $>10 \mu \mathrm{M}$, which resulted in the selective index $>17 \mu \mathrm{M}$ (Table 3; Tong et al., 2018). TLR7/8 agonist R848 (resiquimod) (toll-like receptor (TLR) agonists) inhibited ZIKV RNA synthesis in CHME3, a transformed microglial cell-line [Figure 3(57) and Table 3; Vanwalscappel et al., 2018).

\section{Other Small-Molecule Inhibitors With Undefined Mechanisms}

AV-C(1-(2-fluorophenyl)-2-(5-isopropyl-1,3,4-thiadiazol-2-yl)1,2-dihydrochromeno[2,3-c]pyrrole-3,9-dione) [Figure 3(58)], an interferon-activating agonist of the TRIF pathway, inhibited replication of $\mathrm{ZIKV}\left(\mathrm{IC}_{90}\right)$ of $5.815 \mu \mathrm{M}$ by activating innateand interferon-associated responses, and the $\mathrm{CC}_{50}$ values are well below dosages observed to induce detectable cytotoxicity of THF cells (Table 4; Pryke et al., 2017). Along with Selenium, a free-form amino acid sequence (FFAAP) comprising glycine, cystine, and a glutamate source inhibited ZIKV replication with an $\mathrm{ED}_{90}$ (effective dose at which $90 \%$ of a dose of Zika virus was inhibited) of $2.5 \mathrm{mM}$ in human JEG-3 cells and $4 \mathrm{mM}$ in Vero cells (Table 1; Vasireddi et al., 2019). Histone H3K27 methyltransferases EZH2 and EZH1 (EZH2/1) can suppress gene transcription via propagation of repressive H3K27me3enriched chromatin domains (Margueron and Reinberg, 2011; Di Croce and Helin, 2013; Kim et al., 2015). GSK926 [Figure 3(59)], an inhibitor of histone methyltransferases EZH2/1 (Verma et al., 2012), can suppress not only DNA viruses, like herpes simplex virus (HSV) and human cytomegalovirus (adenovirus) infection, but also an RNA virus, like ZIKV replication, in human foreskin fibroblast (HFF) cells (Table 4; Arbuckle et al., 2017). However, no $\mathrm{IC}_{50}$ was reported. T-705 (favipiravir) [Figure 3(60)], a broad-spectrum antiviral with effects against many viruses, and a structural analog, T-1105, inhibited ZIKV strain SZ01 with an $\mathrm{IC}_{50}$ of $110.9 \pm 13.1$ and $97.5 \pm 6.8 \mu \mathrm{M}$, respectively, and $\mathrm{CC}_{50}>3000 \mu \mathrm{M}$ in Vero cells (Table 4; Cai et al., 2017). Emricasan [Figure 3(61)], a pan-caspase inhibitor, inhibited ZIKV-induced increases in caspase-3 activity with $\mathrm{IC}_{50}$ values of $0.13-0.9 \mu \mathrm{M}$ in SNB-19 cells against three ZIKV strains: FSS13025 (2010 Cambodian strain), MR766 (1947 Ugandan strain), and PRVABC59 (2015 Puerto Rican strain; Table 4; Xu et al., 2016). In addition, in Caspase-3/7 assay, Emricasan also reduced the total number of active (cleaved) caspase-3-expressing forebrain-specific hNPCs (human cortical neural progenitor cells) in both the monolayer and 3-dimensional organoid cultures infected by ZIKV FSS13025 strain (Xu et al., 2016). Two halogenated chrysins, FV13 and FV14 [Figure 3(62,63)], inhibited ZIKV infection with an $\mathrm{IC}_{50}$ of $1.65 \pm 0.86$ and $1.39 \pm 0.11 \mu \mathrm{M}$ in LLC/MK2 cells, respectively (Suroengrit et al., 2017). The $\mathrm{CC}_{50}$ s to the LLC/MK2 cell-based system of FV13 and FV14 were $44.28 \pm 2.90$ and $42.51 \pm 2.53 \mu \mathrm{M}$, respectively (Table 4; Suroengrit et al., 2017). The investigations into the mechanism of these two halogenated chrysin actions suggested multiple targets, but maximal efficiency was achieved with early post-infection treatment (Suroengrit et al., 2017). Compound 1 was confirmed with an inhibitor of ZIKV-induced cytopathic effect (CPE) with an $\mathrm{IC}_{50}$ of $5.95 \mu \mathrm{M}$ and a $\mathrm{CC}_{50}$ of $100 \mu \mathrm{M}$ in human fetal neural stem cells (NSCs) [Figure 3(64) and Table 4; Bernatchez et al., 2018). PKI 14-22 (PKI) [Figure 3(65)], a PKA inhibitor, could act as a potent inhibitor of Asian/American and African lineages of ZIKV replication with an $\mathrm{IC}_{50}$ of about $20 \mu \mathrm{M}$ in endothelial cells and astrocytes by minimal cytotoxicity (Table 4; Cheng et al., 2018). Cavinafungin [Figure 3(66)], targeting ER signal peptidase by binding on SEC11, inhibited ZIKV replication with an $\mathrm{IC}_{50}$ of $150 \mathrm{nM}$ and $\mathrm{CC}_{50}$ of $1650 \mathrm{nM}$ in A549 cells (Table 4; Estoppey et al., 2017). Manidipine and cilnidipine, voltage-gated $\mathrm{Ca}^{2+}$ channel (VGCC) inhibitors, could inhibit ZIKV infection by $100 \%$ with no plaque formation observed at a concentration of $10 \mu \mathrm{M}$ in Vero cells (Wang S. et al., 2017). According to accumulating data, benidipine hydrochloride, pimecrolimus, and nelfinavir mesylate can also inhibit ZIKV replication with a concentration of $10 \mu \mathrm{M}$ in Vero cells [Table 4 and Figure 3(67-69); Wang S. et al., 2017]. Five $2^{\prime}$-C-methylated derivatives of nucleoside analog [nucleosides with a methyl moiety at the $2^{\prime}$-C position of the ribose ring, including $2^{\prime}$-CMA,7-deaza- $2^{\prime}$-CMA, 2'-CMC, 2'-CMG, and $2^{\prime}$-CMU [Figure 3(70-74)], can reduce the viral titer with an $\mathrm{IC}_{50}$ of $5.26 \pm 0.12 \mu \mathrm{M}$ for $2^{\prime}-\mathrm{CMA}, 8.92 \pm 3.32 \mu \mathrm{M}$ for 7 deaza-2'-CMA, $10.51 \pm 0.02 \mu \mathrm{M}$ for $2^{\prime}$-CMC, $22.25 \pm 0.03 \mu \mathrm{M}$ for $2^{\prime}-\mathrm{CMG}$, and $45.45 \pm 0.64 \mu \mathrm{M}$ for $2^{\prime}-\mathrm{CMU}$ in Vero cells (Table 4; Eyer et al., 2016). All these nucleoside analogs showed weak or no cytotoxic effects at a concentration of $100 \mu \mathrm{M}$ on cell proliferation (Eyer et al., 2016). NGI-1 [Figure 3(75)], an aminobenzamide-sulfonamide compound targeting both oligosaccharyltransferase OST isoforms, can block viral RNA replication significantly to inhibit viral particle formation with an $\mathrm{IC}_{50}$ of $2.2 \mu \mathrm{M}$ in HEK293 cells (Table 4; Puschnik et al., 2017). Nordihydroguaiaretic (NDGA) and its methylated derivative, tetra- $O$-methyl nordihydroguaiaretic acid (M4N), disturbed lipid metabolism and sterol regulatory element-binding proteins (SREBP) [Figure 3(76-77)], thereby inhibiting ZIKV PA259459 isolated from a patient with an $\mathrm{IC}_{50}$ of $9.1 \mu \mathrm{M}$ and SI of 17.8 and $\mathrm{IC}_{50}$ of $5.7 \mu \mathrm{M}$ and SI of 187.9, respectively (Table 4; Merino-Ramos et al., 2017). Obatoclax, SaliPhe, and gemcitabine affected ZIKV-mediated transcription [Figure 3(78-80) and Table 4], translation, and posttranslational modifications as well as metabolic pathways, by different mechanisms of action, inhibiting ZIKV infection at non-cytotoxic concentrations (Kuivanen et al., 2017). ZMP STE24, when complexed with proteins of the interferon-induced transmembrane protein (IFITM) family by co-immunoprecipitation studies, inhibited ZIKV viral titer in T98-G cells (Table 1; Fu et al., 2017). PHA-690509 [Figure 3(81)], an investigational compound that functions as a CDKi, inhibited three ZIKV stains with $\mathrm{IC}_{50}$ values of $0.37 \mu \mathrm{M}$, as measured 
TABLE 4 | Other small-molecule inhibitors with undefined mechanisms.

\begin{tabular}{|c|c|c|c|c|c|c|}
\hline $\begin{array}{l}\text { Number of } \\
\text { chemical } \\
\text { structures in } \\
\text { Figure } 3\end{array}$ & Inhibitor & Testing model & Cell lines & $\mathrm{IC}_{50}(\mu \mathrm{M})$ & $\mathrm{CC}_{50}(\mu \mathrm{M})$ & References \\
\hline 58 & $\mathrm{AV}-\mathrm{C}$ & in vitro & THF cells & - & - & Pryke et al. (2017) \\
\hline 59 & GSK926 & in vitro & HFF cells & - & - & Verma et al. (2012) \\
\hline 60 & $\mathrm{~T}-705$ & in vitro & Vero cells & $110.9 \pm 13.1$ & $>3000$ & Cai et al. (2017) \\
\hline 61 & Emricasan & in vitro & SNB-19 cells & $0.13 \sim 0.9$ & - & Xu et al. (2016) \\
\hline 62 & FV13 & in vitro & LLC/MK2 cells & $1.65 \pm 0.86$ & $44.28 \pm 2.90$ & Suroengrit et al. (2017) \\
\hline 63 & FV14 & in vitro & LLC/MK2 cells & $1.39 \pm 0.11$ & $42.51 \pm 2.53$ & Suroengrit et al. (2017) \\
\hline 64 & Compound 1 & in vitro & $\begin{array}{l}\text { Human fetal neural } \\
\text { stem cells }\end{array}$ & 5.95 & 100 & Bernatchez et al. (2018) \\
\hline 65 & PKI 14-22 & in vitro & Endothelial cells & 20 & - & Cheng et al. (2018) \\
\hline 66 & Cavinafungin & in vitro & A549 cells & 150 & 1650 & Estoppey et al. (2017) \\
\hline 67 & Benidipine hydrochloride & in vitro & Vero cells & - & - & Wang S. et al. (2017) \\
\hline 68 & Pimecrolimus & in vitro & Vero cells & - & - & Wang S. et al. (2017) \\
\hline 69 & Nelfinavir mesylate & in vitro & Vero cells & - & - & Wang S. et al. (2017) \\
\hline 70 & $2^{\prime}-\mathrm{CMA}$ & in vitro & Vero cells & $5.26 \pm 0.12$ & - & Eyer et al. (2016) \\
\hline 71 & 7-deaza-2' -CMA & in vitro & Vero cells & $8.92 \pm 3.32$ & - & Eyer et al. (2016) \\
\hline 72 & $2^{\prime}-\mathrm{CMC}$ & in vitro & Vero cells & $10.51 \pm 0.02$ & - & Eyer et al. (2016) \\
\hline 73 & $2^{\prime}-\mathrm{CMG}$ & in vitro & Vero cells & $22.25 \pm 0.03$ & - & Eyer et al. (2016) \\
\hline 74 & $2^{\prime}-\mathrm{CMU}$ & in vitro & Vero cells & $45.45 \pm 0.64$ & - & Eyer et al. (2016) \\
\hline 75 & NGI-1 & in vitro & HEK293 cells & 2.2 & - & Puschnik et al. (2017) \\
\hline 76 & NDGA & in vitro & Vero cells & 9.1 & - & Merino-Ramos et al. (2017) \\
\hline 77 & $\mathrm{M} 4 \mathrm{~N}$ & in vitro & Vero cells & 5.7 & - & Merino-Ramos et al. (2017) \\
\hline 78 & Obatoclax & in vitro & RPE cells & $0.04 \pm 0.01$ & $2.6 \pm 0.4$ & Kuivanen et al. (2017) \\
\hline 79 & SaliPhe & in vitro & RPE cells & $0.05 \pm 0.02$ & $>10$ & Kuivanen et al. (2017) \\
\hline 80 & Gemcitabine & in vitro & RPE cells & 0.01 & $>10$ & Kuivanen et al. (2017) \\
\hline 81 & PHA-690509 & in vitro & SNB-19 cells & 0.37 & - & Xu et al. (2016) \\
\hline
\end{tabular}

by intracellular ZIKV RNA levels in SNB-19 cells (Table 3; Xu et al., 2016).

\section{STRATEGIES FOR DEVELOPING SMALL-MOLECULE ZIKA INHIBITORS}

The development of anti-ZIKV drugs requires effective strategies. For example, using existing drug libraries to screen drug molecules that inhibit new targets is an effective method to develop new drugs (Yang et al., 2017; Kumar et al., 2018). In silicon-based drug modeling, it is another economical and useful strategy to identify candidate drugs in a short amount of time (Pal et al., 2017; Kumar et al., 2018). In addition, virtual screening and electronic pharmacokinetic modeling also facilitate the discovery of effective drug molecules (Rohini et al., 2019). First, the virtual screening method based on electronic pharmacodynamics was adopted to screen effective inhibitors of ZIKV NS2B-NS3 protein from the ASINE database (including 467,802 molecules) (Rohini et al., 2019). Then, the complexes of known NS2B-NS3 protein and its inhibitor were used to establish a five-featured pharmacophore hypothesis, ADDRR, which consists of one hydrogen bond acceptor (A), two hydrogen bond donors (D), and two aromatic rings (R) (Rohini et al., 2019). The pharmacophore model was verified by enrichment analysis before the virtual screening process (Rohini et al., 2019).

Active development of screening methods to assess the antiviral activity of compounds is a key step in the discovery of new drugs (Ekins et al., 2016). Virus replication relies on cellular mechanisms, which means that in vitro experiments use host cells for culture and virus replication. Since ZIKV can infect many different cells, multiple cell lines should be used to study ZIKV infection. The screening of effective drugs using multiple cells provides a good framework for drug discovery (Barr et al., 2016). Other strategies include RNA interference, long non-coding RNAs, miRNAs, interfering peptides, and compounds targeting viral RNA (Han and Mesplede, 2018), underexplored building blocks, and elements introducing into medicinal chemistry (Nitsche et al., 2017).

\section{CONCLUSION}

As an arthropod-borne single-stranded positive RNA virus, ZIKV utilizes a number of host viral proteins and cellular components to accomplish its replication cycle, including the steps of viral entry, genomic replication, structural and nonstructural protein processing, assembly, and budding of virions. Such actions result in a series of congenital abnormities like 
Guillain-Barré syndrome in adults, microcephaly in newborns, and fetal demise during pregnancy (Dick et al., 1952), and the viral and host proteins involved in the virus life cycle can serve as targets for development of small-molecule ZIKV inhibitors. For example, the ZIKV E protein is responsible for the binding of the virus to host cell receptors and mediating viral entry into the host cell; therefore, some small molecule inhibitors targeting the ZIKV E protein are effective in inhibiting virus attachment and entry (Byrd et al., 2013; Fernando et al., 2016; Oo et al., 2019). AXL expressed on human glial cells can permit ZIKV binding and entry into the host glial cells (Nowakowski et al., 2016; Meertens et al., 2017) and small molecule compounds targeting AXL may be effective in inhibiting ZIKV infection (Rausch et al., 2017). However, any compounds targeting host proteins may affect their normal functions and cause adverse effects.

Study has shown that, since the stem region of the ZIKV E protein has high sequence similarity to that of other flavivirues, such as DENV and yellow fever virus (YFV), the ZIKV inhibitor targeting this region is also highly effective against DENV and YFV infection (Yu et al., 2017). Therefore, it is essential to develop small molecule compounds with broad flavivirus inhibitory activity. Another important strategy is to develop small molecule ZIKV inhibitors targeting the different steps of ZIKV replication cycle with a synergistic antiviral effect when they are used in combination.

Numerous cases of ZIKV sexual transmission have been reported during recent ZIKV outbreaks, and studies have shown that ZIKV also replicates in human prostate cells (Spencer et al., 2018). However, little is known about what viral protein(s) and host factor(s) are involved in this event. Therefore, it is essential to identify these proteins as targets for development of smallmolecular inhibitors for preventing sexual transmission of ZIKV.

With the increasing understanding of viral protein structure, tremendous progresses have been made in structure-based

\section{REFERENCES}

Albulescu, I. C., Kovacikova, K., Tas, A., Snijder, E. J., and van Hemert, M. J. (2017). Suramin inhibits Zika virus replication by interfering with virus attachment and release of infectious particles. Antiviral Res. 143, 230-236. doi: 10.1016/j. antiviral.2017.04.016

Arbuckle, J. H., Gardina, P. J., Gordon, D. N., Hickman, H. D., Yewdell, J. W., Pierson, T. C., et al. (2017). Inhibitors of the histone methyltransferases EZH2/1 induce a potent antiviral state and suppress infection by diverse viral pathogens. mBio 8:e01141-17. doi: 10.1128/mBio.01141-17

Baell, J. B., and Holloway, G. A. (2010). New substructure filters for removal of pan assay interference compounds (PAINS) from screening libraries and for their exclusion in bioassays. J. Med. Chem. 53, 2719-2740. doi: 10.1021/jm901137j

Barr, K. L., Anderson, B. D., Prakoso, D., and Long, M. T. (2016). Working with Zika and Usutu Viruses in vitro. PLoS Negl. Trop. Dis. 10:e0004931. doi: 10. 1371/journal.pntd.0004931

Barros, J. B. S., da Silva, P. A. N., Koga, R. C. R., Gonzalez-Dias, P., Carmo Filho, J. R., Nagib, P. R. A., et al. (2018). Acute Zika virus infection in an endemic area shows modest proinflammatory systemic immunoactivation and cytokine-symptom associations. Front. Immunol. 9:821. doi: 10.3389/fimmu. 2018.00821

Bavari, S., Bosio, C. M., Wiegand, E., Ruthel, G., Will, A. B., Geisbert, T. W., et al. (2002). Lipid raft microdomains: a gateway for compartmentalized trafficking of Ebola and Marburg viruses. J. Exp. Med. 195, 593-602. doi: 10.1084/jem. 20011500 discovery of inhibitors targeting the structure and non-structure protein of ZIKV, such as the E protein, three NS2B-NS3 proteinase constructs and helicase, NS5 methyltransferase and polymerase. Several series of small-molecule ZIKV inhibitors targeting these proteins have been reported. However, most of them were tested in vitro while only a small percentage of these compounds have been evaluated in animal models in vivo, and very few have advanced into clinical trials. Therefore, further studies should focus on exploiting novel strategies to identify new anti-ZIKV compounds, elucidating their mechanisms of action, improving the efficacy of antiZIKV compounds, and evaluating the in vivo efficacy and safety of these compounds in suitable animal models and patients. Further development of small-molecule ZIKV inhibitors with high-efficiency and low toxicity will bring promise for clinic treatment of ZIKV infection and related diseases in the near future.

\section{AUTHOR CONTRIBUTIONS}

LW, RL, YG, YL, XD, RX, YZ, and FY drafted the manuscript. TY, $\mathrm{SJ}$, and FY revised and edited the manuscript.

\section{FUNDING}

This work was supported by grants from the National Natural Science Foundation of China (81974302 and 81601761), Hebei Province's Program for Talents Returning from Studying Overseas (CN201707), a starting grant from Hebei Agricultural University (ZD2016026 and YJ201843), and the Program for Youth Talent of Higher Learning Institutions of Hebei Province (BJ2018045).

Bernatchez, J. A., Yang, Z., Coste, M., Li, J., Beck, S., Liu, Y., et al. (2018). Development and validation of a phenotypic high-content imaging assay for assessing the antiviral activity of small-molecule inhibitors targeting Zika virus. Antimicrob. Agents Chemother. 62:AAC.00725-18, doi: 10.1128/AAC.00725-18

Brugger, B., Glass, B., Haberkant, P., Leibrecht, I., Wieland, F. T., and Krausslich, H. G. (2006). The HIV lipidome: a raft with an unusual composition. Proc. Natl. Acad. Sci. U.S.A. 103, 2641-2646. doi: 10.1073/pnas.0511136103

Bullard-Feibelman, K. M., Govero, J., Zhu, Z., Salazar, V., Veselinovic, M., Diamond, M. S., et al. (2017). The FDA-approved drug sofosbuvir inhibits Zika virus infection. Antiviral Res. 137, 134-140. doi: 10.1016/j.antiviral.2016.11.023

Byrd, C. M., Dai, D., Grosenbach, D. W., Berhanu, A., Jones, K. F., Cardwell, K. B., et al. (2013). A novel inhibitor of dengue virus replication that targets the capsid protein. Antimicrob. Agents Chemother. 57, 15-25. doi: 10.1128/AAC.01429-12

Cai, L., Sun, Y., Song, Y., Xu, L., Bei, Z., Zhang, D., et al. (2017). Viral polymerase inhibitors T-705 and T-1105 are potential inhibitors of Zika virus replication. Arch. Virol. 162, 2847-2853. doi: 10.1007/s00705-017-3436-8

Calland, N., Albecka, A., Belouzard, S., Wychowski, C., Duverlie, G., Descamps, V., et al. (2012). (-)-Epigallocatechin-3-gallate is a new inhibitor of hepatitis C virus entry. Hepatology 55, 720-729. doi: 10.1002/hep.24803

Carneiro, B. M., Batista, M. N., Braga, A. C. S., Nogueira, M. L., and Rahal, P. (2016). The green tea molecule EGCG inhibits Zika virus entry. Virology 496, 215-218. doi: 10.1016/j.virol.2016.06.012

Chazal, N., and Gerlier, D. (2003). Virus entry, assembly, budding, and membrane rafts. Microbiol. Mol. Biol. Rev. 67, 226-237. doi: 10.1128/mmbr.67.2.226-237. 2003 
Chen, L., Liu, Y., Wang, S., Sun, J., Wang, P., Xin, Q., et al. (2017). Antiviral activity of peptide inhibitors derived from the protein E stem against Japanese encephalitis and Zika viruses. Antiviral Res. 141, 140-149. doi: 10.1016/j. antiviral.2017.02.009

Chen, Y., Maguire, T., Hileman, R. E., Fromm, J. R., Esko, J. D., Linhardt, R. J., et al. (1997). Dengue virus infectivity depends on envelope protein binding to target cell heparan sulfate. Nat. Med. 3, 866-871. doi: 10.1038/nm0897-866

Cheng, F., Ramos, da Silva, S., Huang, I. C., Jung, J. U., and Gao, S. J. (2018). Suppression of Zika virus infection and replication in endothelial cells and astrocytes by PKA inhibitor PKI 14-22. J Virol 92:e02019-17. doi: 10.1128/JVI. 02019-17

Cho, N. J., Dvory-Sobol, H., Xiong, A., Cho, S. J., Frank, C. W., and Glenn, J. S. (2009). Mechanism of an amphipathic alpha-helical peptide's antiviral activity involves size-dependent virus particle lysis. ACS Chem. Biol. 4, 1061-1067. doi: $10.1021 / \mathrm{cb} 900149 \mathrm{~b}$

Coronado, M. A., Eberle, R. J., Bleffert, N., Feuerstein, S., Olivier, D. S., de Moraes, F. R., et al. (2018). Zika virus NS2B/NS3 proteinase: a new target for an old drug - Suramin a lead compound for NS2B/NS3 proteinase inhibition. Antiviral Res. 160, 118-125. doi: 10.1016/j.antiviral.2018.10.019

Cruz-Oliveira, C., Freire, J. M., Conceicao, T. M., Higa, L. M., Castanho, M. A., and Da Poian, A. T. (2015). Receptors and routes of dengue virus entry into the host cells. FEMS Microbiol. Rev. 39, 155-170. doi: 10.1093/femsre/fuu004

Dai, L., Song, J., Lu, X., Deng, Y. Q., Musyoki, A. M., Cheng, H., et al. (2016). Structures of the Zika Virus envelope protein and its complex with a flavivirus broadly protective antibody. Cell Host. Microbe 19, 696-704. doi: 10.1016/j. chom.2016.04.013

De Clercq, E., and Li, G. (2016). Approved antiviral drugs over the Past 50 Years. Clin. Microbiol. Rev. 29, 695-747. doi: 10.1128/CMR.00102-15

de la Cruz, L., Nguyen, T. H., Ozawa, K., Shin, J., Graham, B., Huber, T., et al. (2011). Binding of low molecular weight inhibitors promotes large conformational changes in the dengue virus NS2B-NS3 protease: fold analysis by pseudocontact shifts. J. Am. Chem. Soc. 133, 19205-19215. doi: 10.1021/ ja208435s

Di Croce, L., and Helin, K. (2013). Transcriptional regulation by Polycomb group proteins. Nat. Struct. Mol. Biol. 20, 1147-1155. doi: 10.1038/nsmb.2669

Dick, G. W., Kitchen, S. F., and Haddow, A. J. (1952). Zika virus. I. Isolations and serological specificity. Trans. R. Soc. Trop. Med. Hyg. 46, 509-520. doi: 10.1016/0035-9203(52)90042-4

Duan, D., Doak, A. K., Nedyalkova, L., and Shoichet, B. K. (2015). Colloidal aggregation and the in vitro activity of traditional Chinese medicines. ACS Chem. Biol. 10, 978-988. doi: 10.1021/cb5009487

Ekins, S., Mietchen, D., Coffee, M., Stratton, T. P., Freundlich, J. S., Freitas-Junior, L., et al. (2016). Open drug discovery for the Zika virus. F1000Res 5:150. doi: 10.12688/f1000research.8013.1

Erbel, P., Schiering, N., D’Arcy, A., Renatus, M., Kroemer, M., Lim, S. P., et al. (2006). Structural basis for the activation of flaviviral NS3 proteases from dengue and West Nile virus. Nat. Struct. Mol. Biol. 13, 372-373. doi: 10.1038/ nsmb1073

Estoppey, D., Lee, C. M., Janoschke, M., Lee, B. H., Wan, K. F., Dong, H., et al. (2017). The natural product cavinafungin selectively interferes with Zika and Dengue virus replication by inhibition of the host signal peptidase. Cell Rep. 19, 451-460. doi: 10.1016/j.celrep.2017.03.071

Eyer, L., Nencka, R., Huvarova, I., Palus, M., Joao Alves, M., Gould, E. A., et al. (2016). Nucleoside inhibitors of Zika virus. J. Infect. Dis. 214, 707-711. doi: 10.1093/infdis/jiw226

Fernando, S., Fernando, T., Stefanik, M., Eyer, L., and Ruzek, D. (2016). An approach for Zika virus inhibition using homology structure of the envelope protein. Mol. Biotechnol. 58, 801-806. doi: 10.1007/s12033-016-9979-1

Fonseca, B. D., Diering, G. H., Bidinosti, M. A., Dalal, K., Alain, T., Balgi, A. D., et al. (2012). Structure-activity analysis of niclosamide reveals potential role for cytoplasmic $\mathrm{pH}$ in control of mammalian target of rapamycin complex 1 (mTORC1) signaling. J. Biol. Chem. 287, 17530-17545. doi: 10.1074/jbc.M112. 359638

Fu, B., Wang, L., Li, S., and Dorf, M. E. (2017). ZMPSTE24 defends against influenza and other pathogenic viruses. J. Exp. Med. 214, 919-929. doi: 10.1084/ jem. 20161270

Germi, R., Crance, J. M., Garin, D., Guimet, J., Lortat-Jacob, H., Ruigrok, R. W., et al. (2002). Heparan sulfate-mediated binding of infectious dengue virus type 2 and yellow fever virus. Virology 292, 162-168. doi: 10.1006/viro.2001. 1232

Hamel, R., Dejarnac, O., Wichit, S., Ekchariyawat, P., Neyret, A., Luplertlop, N., et al. (2015). Biology of Zika virus infection in human skin cells. J. Virol. 89, 8880-8896. doi: 10.1128/JVI.00354-15

Han, Y., and Mesplede, T. (2018). Investigational drugs for the treatment of Zika virus infection: a preclinical and clinical update. Expert Opin. Investig. Drugs 27, 951-962. doi: 10.1080/13543784.2018.1548609

Hasan, S. S., Miller, A., Sapparapu, G., Fernandez, E., Klose, T., Long, F., et al. (2017). A human antibody against Zika virus crosslinks the E protein to prevent infection. Nat. Commun. 8:14722. doi: 10.1038/ncomms14722

Heinz, F. X., and Stiasny, K. (2017). The antigenic structure of Zika Virus and its relation to other flaviviruses: implications for infection and immunoprophylaxis. Microbiol. Mol. Biol. Rev. 81:AAC.1967-1916. doi: 10. 1128/MMBR.00055-16

Isaacs, C. E., Wen, G. Y., Xu, W., Jia, J. H., Rohan, L., Corbo, C., et al. (2008). Epigallocatechin gallate inactivates clinical isolates of herpes simplex virus. Antimicrob. Agents Chemother. 52, 962-970. doi: 10.1128/AAC.00825-07

Jackman, J. A., Costa, V. V., Park, S., Real, A., Park, J. H., Cardozo, P. L., et al. (2018). Therapeutic treatment of Zika virus infection using a brain-penetrating antiviral peptide. Nat. Mater. 17, 971-977. doi: 10.1038/s41563-018-0194-2

Ji, R., Meng, L., Jiang, X., Cvm, N. K., Ding, J., Li, Q., et al. (2014). TAM receptors support neural stem cell survival, proliferation and neuronal differentiation. PLoS One 9:e115140. doi: 10.1371/journal.pone.0115140

Jin, J., Chen, Y. J., Wang, D. C., Ma, L. M., Guo, M., Zhou, C. L., et al. (2018). The inhibitory effect of sodium baicalin on oseltamivir-resistant influenza A virus via reduction of neuraminidase activity. Arch. Pharm. Res. 41, 664-676. doi: 10.1007/s12272-018-1022-6

Jurgeit, A., McDowell, R., Moese, S., Meldrum, E., Schwendener, R., and Greber, U. F. (2012). Niclosamide is a proton carrier and targets acidic endosomes with broad antiviral effects. PLoS Pathog. 8:e1002976. doi: 10.1371/journal.ppat. 1002976

Kim, J. M., Kim, K., Punj, V., Liang, G., Ulmer, T. S., Lu, W., et al. (2015). Linker histone H1.2 establishes chromatin compaction and gene silencing through recognition of H3K27me3. Sci. Rep. 5:16714. doi: 10.1038/srep16714

Kim, Y. M., Gayen, S., Kang, C., Joy, J., Huang, Q., Chen, A. S., et al. (2013). NMR analysis of a novel enzymatically active unlinked dengue NS2B-NS3 protease complex. J. Biol. Chem. 288, 12891-12900. doi: 10.1074/jbc.M112.442723

Kirby, W. M., Hudson, D. G., and Noyes, W. D. (1956). Clinical and laboratory studies of novobiocin, a new antibiotic. AMA Arch. Intern. Med. 98, 1-7.

Kuivanen, S., Bespalov, M. M., Nandania, J., Ianevski, A., Velagapudi, V., De Brabander, J. K., et al. (2017). Obatoclax, saliphenylhalamide and gemcitabine inhibit Zika virus infection in vitro and differentially affect cellular signaling, transcription and metabolism. Antiviral Res. 139, 117-128. doi: 10.1016/j. antiviral.2016.12.022

Kumar, A., Liang, B., Aarthy, M., Singh, S. K., Garg, N., Mysorekar, I. U., et al. (2018). Hydroxychloroquine inhibits Zika virus NS2B-NS3 protease. ACS Omega 3, 18132-18141. doi: 10.1021/acsomega.8b01002

Lee, H., Ren, J., Nocadello, S., Rice, A. J., Ojeda, I., Light, S., et al. (2017). Identification of novel small molecule inhibitors against NS2B/NS3 serine protease from Zika virus. Antiviral Res. 139, 49-58. doi: 10.1016/j.antiviral. 2016.12.016

Lei, J., Hansen, G., Nitsche, C., Klein, C. D., Zhang, L., and Hilgenfeld, R. (2016). Crystal structure of Zika virus NS2B-NS3 protease in complex with a boronate inhibitor. Science 353, 503-505. doi: 10.1126/science.aag2419

Lemke, G., and Rothlin, C. V. (2008). Immunobiology of the TAM receptors. Nat. Rev. Immunol. 8, 327-336. doi: 10.1038/nri2303

Li, C., Deng, Y. Q., Wang, S., Ma, F., Aliyari, R., Huang, X. Y., et al. (2017a). 25Hydroxycholesterol protects host against Zika virus infection and its associated microcephaly in a mouse model. Immunity 46, 446-456. doi: 10.1016/j.immuni. 2017.02.012

Li, C., Zhu, X., Ji, X., Quanquin, N., Deng, Y. Q., Tian, M., et al. (2017b). Chloroquine, a FDA-approved Drug, Prevents Zika virus infection and its associated congenital microcephaly in mice. EBioMedicine 24, 189-194. doi: 10.1016/j.ebiom.2017.09.034

Li, Y., Zhang, Z., Phoo, W. W., Loh, Y. R., Wang, W., Liu, S., et al. (2017c). Structural dynamics of Zika virus NS2B-NS3 protease binding to dipeptide inhibitors. Structure 25:1242-1250.e3. doi: 10.1016/j.str.2017.06.006 
Li, Z., Brecher, M., Deng, Y. Q., Zhang, J., Sakamuru, S., Liu, B., et al. (2017d). Existing drugs as broad-spectrum and potent inhibitors for Zika virus by targeting NS2B-NS3 interaction. Cell Res. 27, 1046-1064. doi: 10.1038/cr.2017. 88

Li, F., Lang, Y., Ji, Z., Xia, Z., Han, Y., Cheng, Y., et al. (2019). A scorpion venom peptide Ev37 restricts viral late entry by alkalizing acidic organelles. J. Biol. Chem. 294, 182-194. doi: 10.1074/jbc.RA118.005015

Li, Y., Zhang, Z., Phoo, W. W., Loh, Y. R., Li, R., Yang, H. Y., et al. (2018). Structural insights into the inhibition of Zika virus NS2B-NS3 protease by a small-molecule inhibitor. Structure 26:555-564.e3. doi: 10.1016/j.str.2018.02. 005

Li, Z., Sakamuru, S., Huang, R., Brecher, M., Koetzner, C. A., Zhang, J., et al. (2018). Erythrosin B is a potent and broad-spectrum orthosteric inhibitor of the flavivirus NS2B-NS3 protease. Antiviral Res. 150, 217-225. doi: 10.1016/j. antiviral.2017.12.018

Lim, H. J., Nguyen, T. T., Kim, N. M., Park, J. S., Jang, T. S., and Kim, D. (2017). Inhibitory effect of flavonoids against NS2B-NS3 protease of ZIKA virus and their structure activity relationship. Biotechnol. Lett. 39, 415-421. doi: 10.1007/ s10529-016-2261-6

Liu, T., Lin, X., Zhou, X., Deng, Z., and Cane, D. E. (2008). Mechanism of thioesterase-catalyzed chain release in the biosynthesis of the polyether antibiotic nanchangmycin. Chem. Biol. 15, 449-458. doi: 10.1016/j.chembiol. 2008.04.006

Lorizate, M., Sachsenheimer, T., Glass, B., Habermann, A., Gerl, M. J., Krausslich, H. G., et al. (2013). Comparative lipidomics analysis of HIV-1 particles and their producer cell membrane in different cell lines. Cell Microbiol. 15, 292-304. doi: $10.1111 / \mathrm{cmi} .12101$

Lozach, P. Y., Burleigh, L., Staropoli, I., Navarro-Sanchez, E., Harriague, J., Virelizier, J. L., et al. (2005). Dendritic cell-specific intercellular adhesion molecule 3-grabbing non-integrin (DC-SIGN)-mediated enhancement of dengue virus infection is independent of DC-SIGN internalization signals. J. Biol. Chem. 280, 23698-23708. doi: 10.1074/jbc.M504337200

Lu, G., Bluemling, G. R., Collop, P., Hager, M., Kuiper, D., Gurale, B. P., et al. (2017). Analysis of ribonucleotide 5'-triphosphate analogs as potential inhibitors of Zika virus RNA-Dependent RNA polymerase by using nonradioactive polymerase assays. Antimicrob. Agents Chemother. 61:AAC.01967-16. doi: 10.1128/AAC.01967-16

Margueron, R., and Reinberg, D. (2011). The Polycomb complex PRC2 and its mark in life. Nature 469, 343-349. doi: 10.1038/nature09784

McGovern, S. L., Caselli, E., Grigorieff, N., and Shoichet, B. K. (2002). A common mechanism underlying promiscuous inhibitors from virtual and highthroughput screening. J. Med. Chem. 45, 1712-1722. doi: 10.1021/jm010533y

Meertens, L., Carnec, X., Lecoin, M. P., Ramdasi, R., Guivel-Benhassine, F., Lew, E., et al. (2012). The TIM and TAM families of phosphatidylserine receptors mediate dengue virus entry. Cell Host. Microbe 12, 544-557. doi: 10.1016/j. chom.2012.08.009

Meertens, L., Labeau, A., Dejarnac, O., Cipriani, S., Sinigaglia, L., Bonnet-Madin, L., et al. (2017). Axl mediates ZIKA virus entry in human glial cells and modulates innate immune responses. Cell Rep. 18, 324-333. doi: 10.1016/j. celrep.2016.12.045

Merino-Ramos, T., Jimenez, de Oya, N., Saiz, J. C., and Martin-Acebes, M. A. (2017). Antiviral activity of nordihydroguaiaretic acid and its derivative Tetra-O-methyl nordihydroguaiaretic acid against west nile virus and Zika virus. Antimicrob. Agents Chemother. 61:AAC.00376-17, doi: 10.1128/AAC. 00376-17

Miner, J. J., Daniels, B. P., Shrestha, B., Proenca-Modena, J. L., Lew, E. D., Lazear, H. M., et al. (2015). The TAM receptor Mertk protects against neuroinvasive viral infection by maintaining blood-brain barrier integrity. Nat. Med. 21, 1464-1472. doi: 10.1038/nm.3974

Moghaddam, E., Teoh, B. T., Sam, S. S., Lani, R., Hassandarvish, P., Chik, Z., et al. (2014). Baicalin, a metabolite of baicalein with antiviral activity against dengue virus. Sci. Rep. 4:5452. doi: 10.1038/srep05452

Mottin, M., Borba, J., Braga, R. C., Torres, P. H. M., Martini, M. C., ProencaModena, J. L., et al. (2018). The A-Z of Zika drug discovery. Drug Discov. Today 23, 1833-1847. doi: 10.1016/j.drudis.2018.06.014

Mounce, B. C., Cesaro, T., Carrau, L., Vallet, T., and Vignuzzi, M. (2017). Curcumin inhibits Zika and chikungunya virus infection by inhibiting cell binding. Antiviral Res. 142, 148-157. doi: 10.1016/j.antiviral.2017.03.014
Musso, D., and Gubler, D. J. (2016). Zika Virus. Clin. Microbiol. Rev. 29, 487-524. doi: 10.1128/CMR.00072-15

Nance, C. L., Siwak, E. B., and Shearer, W. T. (2009). Preclinical development of the green tea catechin, epigallocatechin gallate, as an HIV-1 therapy. J. Allergy Clin. Immunol. 123, 459-465. doi: 10.1016/j.jaci.2008.12.024

Navarro-Sanchez, E., Altmeyer, R., Amara, A., Schwartz, O., Fieschi, F., Virelizier, J. L., et al. (2003). Dendritic-cell-specific ICAM3-grabbing non-integrin is essential for the productive infection of human dendritic cells by mosquitocell-derived dengue viruses. EMBO Rep. 4, 723-728. doi: 10.1038/sj.embor. embor866

Nitsche, C., Passioura, T., Varava, P., Mahawaththa, M. C., Leuthold, M. M., Klein, C. D., et al. (2019). De novo discovery of nonstandard macrocyclic peptides as noncompetitive inhibitors of the Zika virus NS2B-NS3 protease. ACS Med. Chem. Lett. 10, 168-174. doi: 10.1021/acsmedchemlett.8b00535

Nitsche, C., Zhang, L., Weigel, L. F., Schilz, J., Graf, D., Bartenschlager, R., et al. (2017). Peptide-boronic acid inhibitors of flaviviral proteases: medicinal chemistry and structural biology. J. Med. Chem. 60, 511-516. doi: 10.1021/acs. jmedchem.6b01021

Nowakowski, T. J., Pollen, A. A., Di Lullo, E., Sandoval-Espinosa, C., Bershteyn, M., and Kriegstein, A. R. (2016). Expression analysis highlights AXL as a Candidate Zika virus entry receptor in neural stem cells. Cell Stem Cell 18, 591-596. doi: 10.1016/j.stem.2016.03.012

Nyboe Andersen, A., Nelson, S. M., Fauser, B. C., Garcia-Velasco, J. A., Klein, B. M., Arce, J. C., et al. (2017). Individualized versus conventional ovarian stimulation for in vitro fertilization: a multicenter, randomized, controlled, assessor-blinded, phase 3 noninferiority trial. Fertil. Steril. 107, 387-396.e4. doi: 10.1016/j.fertnstert.2016.10.033

Olsen, D. B., Eldrup, A. B., Bartholomew, L., Bhat, B., Bosserman, M. R., Ceccacci, A., et al. (2004). A 7-deaza-adenosine analog is a potent and selective inhibitor of hepatitis $\mathrm{C}$ virus replication with excellent pharmacokinetic properties. Antimicrob. Agents Chemother. 48, 3944-3953. doi: 10.1128/AAC.48.10.39443953.2004

Oo, A., Rausalu, K., Merits, A., Higgs, S., Vanlandingham, D., Abu Bakar, S., et al. (2018). Deciphering the potential of baicalin as an antiviral agent for Chikungunya virus infection. Antiviral Res. 150, 101-111. doi: 10.1016/j. antiviral.2017.12.012

Oo, A., Teoh, B. T., Sam, S. S., Bakar, S. A., and Zandi, K. (2019). Baicalein and baicalin as Zika virus inhibitors. Arch. Virol. 164, 585-593. doi: 10.1007/s00705018-4083-4

Pal, P., Misra, G., and Mathur, P. (2017). In silico screening of small molecule modulators of Zika virus proteins . Noida: IEEE.

Passioura, T., Katoh, T., Goto, Y., and Suga, H. (2014). Selection-based discovery of druglike macrocyclic peptides. Annu. Rev. Biochem. 83, 727-752. doi: 10.1146/ annurev-biochem-060713-035456

Perera-Lecoin, M., Meertens, L., Carnec, X., and Amara, A. (2013). Flavivirus entry receptors: an update. Viruses 6, 69-88. doi: 10.3390/v6010069

Petersen, L. R., Jamieson, D. J., Powers, A. M., and Honein, M. A. (2016). Zika Virus. N. Engl. J. Med. 374, 1552-1563. doi: 10.1056/NEJMra1602113

Phoo, W. W., Li, Y., Zhang, Z., Lee, M. Y., Loh, Y. R., Tan, Y. B., et al. (2016). Structure of the NS2B-NS3 protease from Zika virus after self-cleavage. Nat. Commun. 7:13410. doi: 10.1038/ncomms13410

Phoo, W. W., Zhang, Z., Wirawan, M., Chew, E. J. C., Chew, A. B. L., Kouretova, J., et al. (2018). Structures of Zika virus NS2B-NS3 protease in complex with peptidomimetic inhibitors. Antiviral Res. 160, 17-24. doi: 10.1016/j.antiviral. 2018.10.006

Pierson, T. C., and Kielian, M. (2013). Flaviviruses: braking the entering. Curr. Opin. Virol. 3, 3-12. doi: 10.1016/j.coviro.2012.12.001

Pryke, K. M., Abraham, J., Sali, T. M., Gall, B. J., Archer, I., Liu, A., et al. (2017). A novel agonist of the TRIF pathway induces a cellular state refractory to replication of Zika, Chikungunya, and dengue viruses. mBio 8:e0452-17. doi: 10.1128/mBio.00452-17

Puschnik, A. S., Marceau, C. D., Ooi, Y. S., Majzoub, K., Rinis, N., Contessa, J. N., et al. (2017). A small-molecule oligosaccharyltransferase inhibitor with pan-flaviviral activity. Cell Rep. 21, 3032-3039. doi: 10.1016/j.celrep.2017. 11.054

Ramharack, P., and Soliman, M. E. S. (2018). Zika virus NS5 protein potential inhibitors: an enhanced in silico approach in drug discovery. J. Biomol. Struct. Dyn. 36, 1118-1133. doi: 10.1080/07391102.2017.1313175 
Rausch, K., Hackett, B. A., Weinbren, N. L., Reeder, S. M., Sadovsky, Y., Hunter, C. A., et al. (2017). Screening bioactives reveals nanchangmycin as a broad spectrum antiviral active against Zika Virus. Cell Rep. 18, 804-815. doi: 10.1016/ j.celrep.2016.12.068

Rocker, A. E., Muller, J. A., Dietzel, E., Harms, M., Kruger, F., Heid, C., et al. (2018). The molecular tweezer CLR01 inhibits Ebola and Zika virus infection. Antiviral Res. 152, 26-35. doi: 10.1016/j.antiviral.2018.02.003

Rohini, K., Agarwal, P., Preethi, B., Shanthi, V., and Ramanathan, K. (2019). Exploring the lead compounds for Zika Virus NS2B-NS3 protein: an e-pharmacophore-based approach. Appl. Biochem. Biotechnol. 187, 194-210. doi: 10.1007/s12010-018-2814-3

Roy, A., Lim, L., Srivastava, S., Lu, Y., and Song, J. (2017). Solution conformations of Zika NS2B-NS3pro and its inhibition by natural products from edible plants. PLoS One 12:e180632. doi: 10.1371/journal.pone.0180632

Sahoo, M., Jena, L., Daf, S., and Kumar, S. (2016). Virtual screening for potential inhibitors of NS3 protein of Zika Virus. Genomics Inform. 14, 104-111. doi: 10.5808/GI.2016.14.3.104

Shannon, A. E., Pedroso, M. M., Chappell, K. J., Watterson, D., Liebscher, S., Kok, W. M., et al. (2016). Product release is rate-limiting for catalytic processing by the Dengue virus protease. Sci. Rep. 6:37539. doi: 10.1038/srep37539

Shi, Y., and Gao, G. F. (2017). Structural Biology of the Zika Virus. Trends Biochem. Sci. 42, 443-456. doi: 10.1016/j.tibs.2017.02.009

Shiryaev, S. A., Farhy, C., Pinto, A., Huang, C. T., Simonetti, N., Elong Ngono, A., et al. (2017). Characterization of the Zika virus two-component NS2BNS3 protease and structure-assisted identification of allosteric small-molecule antagonists. Antiviral Res. 143, 218-229. doi: 10.1016/j.antiviral.2017.04.015

Singh, A., and Jana, N. K. (2017). Discovery of potential Zika virus RNA polymerase inhibitors by docking-based virtual screening. Comput. Biol. Chem. 71, 144151. doi: 10.1016/j.compbiolchem.2017.10.007

Song, J., and Ni, F. (1998). NMR for the design of functional mimetics of proteinprotein interactions: one key is in the building of bridges. Biochem. Cell Biol. 76, $177-188$.

Song, J. M., Lee, K. H., and Seong, B. L. (2005). Antiviral effect of catechins in green tea on influenza virus. Antiviral Res. 68, 66-74. doi: 10.1016/j.antiviral.2005.06.010

Spencer, J. L., Lahon, A., Tran, L. L., Arya, R. P., Kneubehl, A. R., Vogt, M. B., et al. (2018). Replication of Zika Virus in human prostate cells: a potential source of sexually transmitted virus. J. Infect. Dis. 217, 538-547. doi: 10.1093/infdis/ jix436

Stephen, P., Baz, M., Boivin, G., and Lin, S. X. (2016). Structural insight into NS5 of Zika virus leading to the discovery of MTase inhibitors. J. Am. Chem. Soc. 138, 16212-16215. doi: 10.1021/jacs.6b10399

Suroengrit, A., Yuttithamnon, W., Srivarangkul, P., Pankaew, S., Kingkaew, K., Chavasiri, W., et al. (2017). Halogenated chrysins inhibit dengue and Zika virus infectivity. Sci. Rep. 7:13696. doi: 10.1038/s41598-017-14121-5

Tong, X., Smith, J., Bukreyeva, N., Koma, T., Manning, J. T., Kalkeri, R., et al. (2018). Merimepodib, an IMPDH inhibitor, suppresses replication of Zika virus and other emerging viral pathogens. Antiviral Res. 149, 34-40. doi: 10.1016/j. antiviral.2017.11.004

Tritsch, D., Zingle, C., Rohmer, M., and Grosdemange-Billiard, C. (2015). Flavonoids: true or promiscuous inhibitors of enzyme? The case of deoxyxylulose phosphate reductoisomerase. Bioorg. Chem. 59, 140-144. doi: 10.1016/j.bioorg.2015.02.008

Vanwalscappel, B., Tada, T., and Landau, N. R. (2018). Toll-like receptor agonist R848 blocks Zika virus replication by inducing the antiviral protein viperin. Virology 522, 199-208. doi: 10.1016/j.virol.2018.07.014

Vasireddi, M., Crum, A., May, H., Katz, D., and Hilliard, J. (2019). A novel antiviral inhibits Zika virus infection while increasing intracellular glutathione biosynthesis in distinct cell culture models. Antiviral Res. 161, 46-52. doi: 10.1016/j.antiviral.2018.09.004

Verma, S. K., Tian, X., LaFrance, L. V., Duquenne, C., Suarez, D. P., Newlander, K. A., et al. (2012). Identification of Potent, Selective, Cell-active inhibitors of the histone lysine methyltransferase EZH2. ACS Med. Chem. Lett. 3, 1091-1096. doi: $10.1021 / \mathrm{ml} 3003346$
Wang, C., Yang, S. N. Y., Smith, K., Forwood, J. K., and Jans, D. A. (2017). Nuclear import inhibitor $\mathrm{N}$-(4-hydroxyphenyl) retinamide targets Zika virus (ZIKV) nonstructural protein 5 to inhibit ZIKV infection. Biochem. Biophys. Res. Commun. 493, 1555-1559. doi: 10.1016/j.bbrc.2017.10.016

Wang, S., Liu, Y., Guo, J., Wang, P., Zhang, L., Xiao, G., et al. (2017). Screening of FDA-approved drugs for inhibitors of Japanese encephalitis virus infection. $J$ Virol 91:e01055-17. doi: 10.1128/JVI.01055-17

Wang, X., Zou, P., Wu, F., Lu, L., and Jiang, S. (2017). Development of smallmolecule viral inhibitors targeting various stages of the life cycle of emerging and re-emerging viruses. Front. Med. 11:449-461. doi: 10.1007/s11684-0170589-5

Wang, Z. Y., Wang, Z., Zhen, Z. D., Feng, K. H., Guo, J., Gao, N., et al. (2017). Axl is not an indispensable factor for Zika virus infection in mice. J. Gen. Virol. 98, 2061-2068. doi: 10.1099/jgv.0.000886

Wang, Z., Wang, P., and An, J. (2016). Zika virus and Zika fever. Virol. Sin. 31, 103-109. doi: 10.1007/s12250-016-3780-y

Xu, H. T., Hassounah, S. A., Colby-Germinario, S. P., Oliveira, M., Fogarty, C., Quan, Y., et al. (2017). Purification of Zika virus RNA-dependent RNA polymerase and its use to identify small-molecule Zika inhibitors. J. Antimicrob. Chemother. 72, 727-734. doi: 10.1093/jac/dkw514

Xu, M., Lee, E. M., Wen, Z., Cheng, Y., Huang, W. K., Qian, X., et al. (2016). Identification of small-molecule inhibitors of Zika virus infection and induced neural cell death via a drug repurposing screen. Nat. Med. 22, 1101-1107. doi: $10.1038 / \mathrm{nm} .4184$

Yang, H. T., Ju, J. H., Wong, Y. T., Shmulevich, I., and Chiang, J. H. (2017). Literature-based discovery of new candidates for drug repurposing. Brief Bioinform. 18, 488-497. doi: 10.1093/bib/bbw030

Yu, Y., Deng, Y. Q., Zou, P., Wang, Q., Dai, Y., Yu, F., et al. (2017). A peptide-based viral inactivator inhibits Zika virus infection in pregnant mice and fetuses. Nat. Commun. 8:15672. doi: 10.1038/ncomms15672

Yuan, S., Chan, J. F., den-Haan, H., Chik, K. K., Zhang, A. J., Chan, C. C., et al. (2017). Structure-based discovery of clinically approved drugs as Zika virus NS2B-NS3 protease inhibitors that potently inhibit Zika virus infection in vitro and in vivo. Antiviral Res. 145, 33-43. doi: 10.1016/j.antiviral.2017. 07.007

Zandi, K., Teoh, B. T., Sam, S. S., Wong, P. F., Mustafa, M. R., and Abubakar, S. (2012). Novel antiviral activity of baicalein against dengue virus. BMC Complement. Altern. Med. 12:214. doi: 10.1186/1472-6882$12-214$

Zelensky, A. N., and Gready, J. E. (2005). The C-type lectin-like domain superfamily. FEBS J. 272, 6179-6217. doi: 10.1111/j.1742-4658.2005.05031.x

Zhang, Z., Li, Y., Loh, Y. R., Phoo, W. W., Hung, A. W., Kang, C., et al. (2016). Crystal structure of unlinked NS2B-NS3 protease from Zika virus. Science 354, 1597-1600. doi: 10.1126/science.aai9309

Zhao, Y., and Tan, W. (2015). [Advances in the researches of genomic characterization and molecular detection of Middel East respiratory syndrome coronavirus]. Zhonghua Yu Fang Yi Xue Za Zhi 49, 461-464.

Zmurko, J., Marques, R. E., Schols, D., Verbeken, E., Kaptein, S. J., and Neyts, J. (2016). The Viral Polymerase inhibitor 7-Deaza-2'-C-Methyladenosine Is a Potent inhibitor of In Vitro Zika virus replication and delays disease progression in a robust mouse infection model. PLoS Negl. Trop. Dis. 10:e0004695. doi: 10.1371/journal.pntd.0004695

Conflict of Interest: The authors declare that the research was conducted in the absence of any commercial or financial relationships that could be construed as a potential conflict of interest.

Copyright (c) 2019 Wang, Liang, Gao, Li, Deng, Xiang, Zhang, Ying, Jiang and Yu. This is an open-access article distributed under the terms of the Creative Commons Attribution License (CC BY). The use, distribution or reproduction in other forums is permitted, provided the original author(s) and the copyright owner(s) are credited and that the original publication in this journal is cited, in accordance with accepted academic practice. No use, distribution or reproduction is permitted which does not comply with these terms. 